\title{
Physical activity and quality of life among college students without comorbidities for cardiometabolic diseases: systematic review and meta-analysis
}

\author{
Lívia Carvalho Sette Abrantes ${ }^{1,2}$ ( Núbia de Souza de Morais $^{2} \cdot$ Vivian Siqueira Santos Gonçalves ${ }^{3}$ [D . \\ Sarah Aparecida Vieira Ribeiro ${ }^{2}$ (1) Catarina Maria Nogueira de Oliveira Sediyama ${ }^{4}$. \\ Sylvia do Carmo Castro Franceschini ${ }^{2}$ (1) Paulo Roberto dos Santos Amorim ${ }^{5}$ (D) Silvia Eloiza Priore ${ }^{2}(\mathbb{D}$
}

Accepted: 3 November 2021 / Published online: 20 November 2021

(C) The Author(s), under exclusive licence to Springer Nature Switzerland AG 2021

\begin{abstract}
Purpose To systematically review studies on the relationship between physical activity (PA) and quality of life (QOL) in university students without comorbidities for cardiometabolic diseases from around the world.

Methods We included observational studies with university students of both sexes, from public or private institutions, and that investigated the association or correlation between physical activity and quality of life among these students, without delimitation of date, language, or location. Reviews, letters to the editors, studies with qualitative methodologies, case studies, book chapters, articles with college students who had some specific disease or condition, such as obesity, diabetes, and others; studies with children of parents with chronic diseases, and those that were institutions aimed only at very specific populations, were excluded. Meta-analysis was calculated.

Results Thirty studies, consisting of 19,731 students, were included. The most commonly used instruments to assess the quality of life of the university population were the Quality of Life Questionnaire—short version (WHOQOL-BREF), and the Medical Outcomes Study 36-Item Short-Form Health Survey (SF-36). The International Physical Activity Questionnaire (IPAQ) was the most commonly used instrument to assess PA. For the meta-analysis, 22 studies were included. Weak but positive correlations were found between PA and the QOL domains: physical health $\left(0.16 .95 \%\right.$ CI $0.110 .22 ; I^{2}=99.96 \%$ ); mental health $\left(0.14 ; 95 \%\right.$ CI $\left.0.07-0.20 ; I^{2}=99.97 \%\right)$; social relations $\left(0.24,95 \%\right.$ CI $\left.0.08-0.38 ; I^{2}=99.99 \%\right)$; environment $\left(0.23,95 \%\right.$ CI $\left.0.14-0.32 ; I^{2}=99.90 \%\right)$; vitality $\left(0.17 .95 \%\right.$ CI $\left.0.15-0.20 ; I^{2}=99.49 \%\right)$ pain $(0.02 .95 \%$ CI -0.02 to 0.12 ; $\left.I^{2}=99.96 \%\right)$; QOL and PA $\left(0.21,95 \%\right.$ CI $\left.0.08-0.34 ; I^{2}=99.99 \%\right)$. An association of $R=0.60\left(95 \%\right.$ CI $\left.0.25-0.95 ; I^{2}=85.61 \%\right)$ was found between QOL and PA in total.

Conclusion The results of our study showed a weak but positive relationship between physical activity and overall quality of life in college students, and also between PA and the domains of QL: physical health, social relationships, mental health, environment, and vitality, in this same population. It is important to study this population, since risk behaviors in this phase tend to perpetuate in the other phases of life.
\end{abstract}

Keywords Physical activity · University students $\cdot$ Higher education · Quality of life · Systematic review $\cdot$ Meta-analysis

\section{Introduction}

Physical inactivity is a public health problem worldwide. It is estimated that in $2017,31.1 \%$ of the world adult population was below the American College of Sports Medicine

Lívia Carvalho Sette Abrantes

li.viasette@hotmail.com

Extended author information available on the last page of the article recommendations (150 min of moderate physical activity (PA)/week or 75 min of vigorous PA/week) for PA practice [1-3]. According to the World Health Organization, sedentary lifestyles favor the onset of non-communicable diseases and injuries (NCDs) and are one of the factors responsible for most deaths caused by these diseases [4]. In addition, the literature shows that PA practice is related to improved health, well-being, an improved biochemical profile, as well as positively influencing mood and anxiety. 
PA contributes to reducing the risk of NCDs and improving quality of life (QoL) [1, 5-7].

A longitudinal study conducted from 1997 to 2014 with a representative sample of US adults showed that individuals who engaged in at least 150 min of moderate-intensity aerobic PA, 75 min of vigorous-intensity aerobic PA per week, or a combination of the two, with moderate muscle strengthening activities twice a week or more, had a lower risk of all-cause mortality compared to those who did not exercise regularly [8]. Kallio et al. (2020) [9] observed that during two years of follow-up at school, students showed a reduction in daily PA time, with a consequent increase in sedentary time. These results demonstrate that with an increase in time spent studying as individuals age, there is a reduction in time allocated to PA.

It is important to consider that academic life brings great challenges and difficulties. It is a period when most students move to another city or even state, often leaving their parents' home for the first time and becoming responsible for themselves. Still, with the increased time spent on studies and extracurricular activities at university, leisure time is restricted, which leads to the interruption or reduction of PA practice upon entering higher education [10, 11]. Corroborating this information, a survey conducted in 23 countries showed that the prevalence of physically inactive university students ranged from 21.9 to $80.6 \%$ [12-14].

It is noteworthy that increased physical inactivity coincides with higher rates of obesity, increasing the risk of health problems, and reducing the QoL of individuals [15]. QoL can be assessed by different domains: physical; mental; environmental; social relationships; access to food, health and education; pain; housing; commuting; in addition to financial issues [16]. It can be affected by various factors, such as the individual's routine and the stages they are in. Therefore, higher education and all the changes arising from it can influence the QoL of college students [17-19]. Encouraging PA should be one of the world's public policy priorities, especially in middle-income countries. Its practice is beneficial at any age, but it is important to pay attention to some population groups, such as these students, due to the challenges they face during this period of life. Moreover, the behaviors adopted and consolidated during this period tend to remain in during the other stages of life, influencing future health $[15,20]$.

Given the above, it is important to better understand PA as a factor influencing the QoL of college students around the world. After searching the literature, no studies were found to provide a comprehensive overview of this relationship, thus a systematic review with meta-analysis on this subject may help fill this gap. Given this context, our aim was to systematically review studies on the relationship between physical activity (PA) and quality of life (QOL) in university students without comorbidities for cardiometabolic diseases from around the world.

\section{Methodology}

\section{Protocol and registration}

This systematic review followed the Preferred Reporting Items for Systematic Reviews and Meta-analyses (PRISMA) checklist [21]. This review was registered in the International Prospective Registry of Systematic Reviews (PROSPERO): Number CRD42020197289.

\section{Eligibility criteria}

Studies with university students of both sexes were included; of any educational institution, whether public or private. Studies that investigated the correlation or association between levels of physical activity and quality of life in general or between domains of it, published on any dates, languages, or locations.

Review articles, letters to the editors, studies with qualitative methodologies, case studies, book chapters, articles with university students who had some specific disease or condition, such as obesity, diabetes, among others; studies with children of parents with chronic diseases, and those directed only to very specific populations were excluded.

\section{Information sources and search strategy}

The search strategy was developed based on the list of recommendations from the Peer Review of Electronic Search Strategies (PRESS) [22] and later sent for review to two researchers with experience in Systematic Reviews.

To search for the studies, the following databases were used: MEDLINE, LILACS, Embase, Scopus, Web of Science, Google Scholar and ProQuest Dissertation \& Theses Global.

The search strategy used for MEDLINE was as follows: ("College Student"[Title/Abstract] OR "University student"[Title/Abstract] OR Student[Title/Abstract] OR Undergraduate[Title/Abstract] OR "Bachelor's degree"[Title/Abstract] OR University[Title/Abstract] OR Universities[Title/Abstract] OR Faculty[Title/Abstract] OR Academy[Title/Abstract]) AND ("Physical activity level"[Title/Abstract] OR "Physical activity"[Title/ Abstract] OR "Sedentary behavior"[Title/Abstract] OR "Sedentary lifestyle"[Title/Abstract]) AND ("Quality of life"[Title/Abstract] OR Lifestyle[Title/Abstract] OR "Life quality"[Title/Abstract] OR "Health-related quality of Life"[Title/Abstract] OR "Health related quality of life"[Title/Abstract] OR HRQOL[Title/Abstract]) AND 
(Observational OR "Observational Study" OR Survey OR "Cross-sectional" OR Cohort OR "Case-control" OR Intervention OR "Intervention study" OR "Clinical Trial" OR "Clinical study" OR "Randomized controlled trial" OR RCT OR Association OR Relationship OR Correlation). For the other six databases, the search strategy was adapted according to their peculiarities (Appendix 1).

The searches started and ended in August 2020. In addition, the references of the included articles were inspected in order to identify qualified articles for review.

\section{Selection of studies and data extraction}

The selection of studies was performed in two stages, by two researchers independently (LCSA and NSM). In the first stage, articles were selected by title and abstract. Always following the eligibility criteria. In the second, the selected ones were read in full and selected. Then, the two researchers met to resolve any disagreements about the selection. In addition, a search was performed in the reference lists of selected articles. The participation of a third researcher was not necessary, as all discrepancies between the two main ones were resolved. When there was an absence of information in the articles, the authors were contacted at least twice in order to obtain this data.

Subsequently, the characteristics of the studies were organized into three tables containing information as follows: Author and year; study country; sample (n sample, sex and age); study design, aim of the study; instruments for assessing physical activity and quality of life and their respective final or domain scores; statistical test used, adjustment variables, main results, and finally the following question: "Is physical activity related to quality of life?".

\section{Risk of bias within individual studies}

The critical tool recommended by the Joanna Briggs Institute for adapted cross-sectional studies was used to assess the risk of bias [23].

The tool consists of eight questions: "Inclusion criteria clearly defined in the sample"; "Subjects of study and environment described in detail"; "Exposure measured in a valid and reliable way"; "Clearly defined objectives and inclusion and exclusion criteria"; "Confounding factors identified"; "Strategies for dealing with confounding factors"; "Results measured in a valid and reliable way"; "Adequate statistical analysis" [23].

The questions were answered as "yes", "no", "unclear", or "not applicable". If all answers are "yes", in all items, the risk of bias will be low and if any item is classified as "no", a high risk of bias will be expected [23]. The evaluation of risk of bias was not used as eligibility criteria for inclusion of articles.

\section{Summary measures and data analysis}

When quantitative data were available, meta-analyses were performed to: (1) verify the correlation between the scores of the instruments for assessing QOL (and its components) and the practice of PA (Always having analyzed the highest level of physical activity practice, when this data was available in the original articles); and (2) estimate the magnitude of the association between the scores of the instruments for assessing QOL and the practice of PA.

Random models were used for meta-analysis, with effect estimation using the Maximum Likelihood method (Maximum-likelihood). The meta-analysis random effects assumes that different studies estimate different intervention effects, although related [24, 25], which agrees with our data.

In the case of studies where the measure of effect was the correlation, the authors did not present the error estimates (Standard Error, Standard Deviation, Confidence Interval, or Variance) necessary for their performance. Thus, we proceeded to obtain the correlation coefficient (r) transformed to the $\mathrm{Z}$-value [26], where:

$\mathrm{Z}=0.5 * \ln ((1+\mathrm{r}) /(1-\mathrm{r}))$.

(ln: natural log; r: correlation coefficient).

The $\mathrm{z}$-value was used because it presents a normal approximate distribution and its variance can be estimated by the formula (ref):

Variance $=1 /(\mathrm{n}-3)(\mathrm{n}=$ number of participants for each article).

After summarizing the results and calculating the respective Confidence Intervals (95\% CI), the measurements were again transformed into a correlation coefficient for better interpretation of the results and presented using Forest Graphics.

For studies that investigated the association between exposures and outcomes of interest through regression analysis, the summary measure was presented using the $\beta$ coefficient, accompanied by the respective $95 \%$ CI.

The heterogeneity of treatment effects between studies was tested using the Chi-square method $(p<0.10)$ [27] and its magnitude using $I^{2}$. Due to the reduced number of studies included in the meta-analysis, it was not possible to perform meta-regression and analysis of publication bias, according to the recommendation of protocols by Cochrane [25]. All tests were performed using the Stata Software, version 16, serial number 301606311865 , using the "meta" command. 


\section{Results}

\section{Selection of studies}

Figure 1 shows the steps for selecting articles and those included in the review. Appendix 2 shows the excluded articles and the reason for the exclusion of each one [3, 5, 28-69].

\section{Study characteristics}

There was no response from the contacted authors to obtain missing data. Table 1 shows the general characteristics of the studies. After the analysis, 30 articles were included, all with cross-sectional design. With individuals of both sexes and published in the years 2011 to 2020 .

The studies were developed in several countries around the world: Brazil [7, 70, 71]; the USA [14, 72-77]]; Turkey [78-81]; Korea [82, 83]; China [13, 84]; Croatia [85, 86]; Taiwan [12]; Pakistan [87]; South Africa [88]; Colombia [89]; Italy [90]; Venezuela [91]; Poland [92]; Serbia [93]; Iran [94]; and Vietnam [95]. The total sample was 19,731 individuals. The general objective of each study and other characteristics are shown in Table 1.

\section{Risk of bias within individual studies}

The risk of bias assessment was carried out by two researchers (LCSA e NSM), independently and at the end of it, both
Fig. 1 Flow diagram of the literature search and selection criteria ( Adapted from PRISMA)

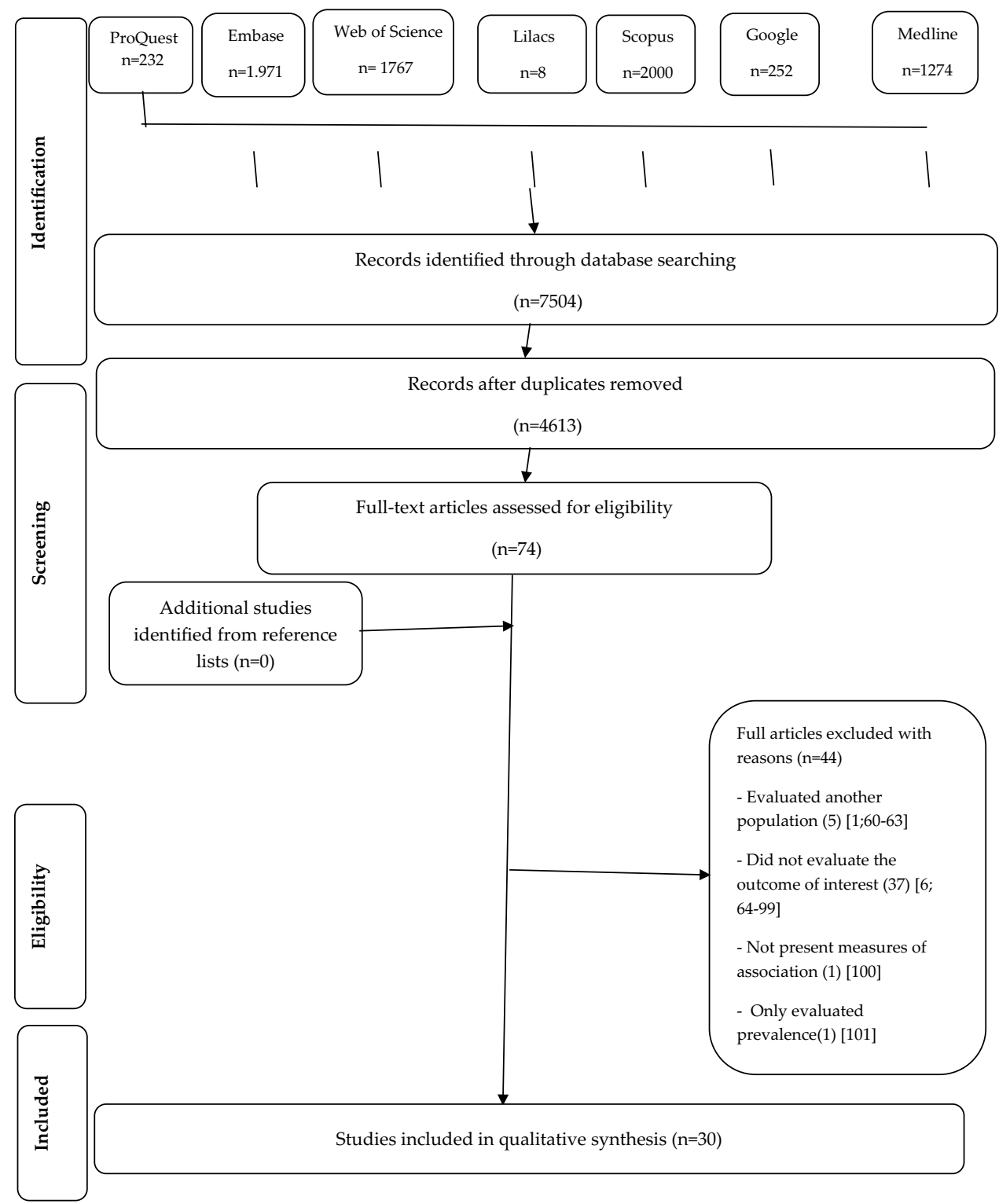


Table 1 Description of included studies

\begin{tabular}{lll}
\hline Author/year & Country & Sample (n. sex. age) \\
\hline Chang et al. [16] & Taiwan & 1230. Both sexes. 18-25 years \\
Çiçek [17] & Turkey & 150. Both sexes. 20.67 \pm 1.65 years \\
Dunn (2011) & EUA & 243. F. 18-27 $(21.0 \pm 1.70)$ years
\end{tabular}

Ge et al. [13]

Goldsby [72]

Park and Kim [81]

Joo [82]

Joseph et al. [73]

Khan and Hassansdra [86]

Kılınç et al. [78]

Kocaaga et al. [79]

Kokic et al. [84]

Kruger and Sonono [87]

Legey et al. [7]
China

EUA

Korea

Korea

USA

590. Both sexes. $20.4 \pm 1.7$ years

Pakistan 378. Both sexes. 18-48 years

Turkey

150. Female. $17-28$ years

Turkey

30. F. 18-26 years

Croatia

517. Both sexes. $20 \pm 2$ years

South Africa 703 . Both sexes. $19.6 \pm 1.26$ years

Brazil

140. Both sexes. $23.6 \pm 3.7$ years
Study design Aim of the study

Cross-sectional To investigate associations between current exercise participation, sleep quality, and QoL among university students in Taiwan

Cross-sectional To investigate Physical Activity (PA) and QoL of students in the SDS and ODS who attend the university

Cross-sectional To investigate the relationships among individual (self-efficacy and enjoyment), social environmental factors (family and friend support), physical environmental factors (residential density, pedestrian infrastructure, proximity of recreational facilities, street connectivity, aesthetic quality, land use mix, traffic safety, and crime safety), PA and HRQoL in female college students

Cross-sectional To evaluate the association between physical activity, sedentary time, and sleep duration in the HRQoL of university students in Northeast China

Cross-sectional To evaluate the relationship between HRQOL variables, MVPA, and BMI

Cross-sectional To identify the relationships between PA, health status, and QoL of university students

Cross-sectional To analyze the associations between PA and stress, interpersonal relationships, and the QoL in university students

Cross-sectional To add to the limited body of research examining the relationship between PA and QoL in young adults

Cross-sectional To explore the associations between PA, QoL, and psychological health related among university students in Pakistan

Cross-sectional To determine the relationship between the QoL of female students studying at Yüzüncü Yıl University and their levels of PA

Cross-sectional To investigate the relationship between PA, FC, QoL, and sleep quality in healthy adults

Cross-sectional To determine and compare PA levels, health-HRQoL, and the prevalence of musculoskeletal pain symptoms (MPS) among the students of Physiotherapy and Social Sciences

Cross-sectional To investigate the role of psychosomatic problems in the relationship between PA and HRQo L

Cross-sectional Investigate the relationship of PA level and their domains with HRQL, mood state (MS), and anxiety 
Table 1 (continued)

\begin{tabular}{lll}
\hline Author/year & Country & Sample (n. sex. age) \\
\hline Lemos et al. [84] & Colo mbia & 237. Both sexes. 20.6 \pm 2.2 years \\
Maciel et al. [69] & Brazil & 1966. Both sexes. $30.4 \pm 12.4$ years
\end{tabular}

Study design Aim of the study

1966. Both sexes. $30.4 \pm 12.4$ years

Cross-sectional To determine the level of QoL in college students' health areas and evaluate associated factors

Mak et al. [83]

Massidda et al. [89]

Italy

155. Both sexes. $18-30$ years

Mendoza et al. [90]

Nieves (2017)

Nowak et al. [91]

Poland

595. Both sexes. $18-30$ years

Pedišić et al. [85]

Pekmezovic et al. [92]

Serbia

1624. Both sexes. $20.8 \pm 1.8$ years

Peleias et al. [70]

Brazil

Pourranjbar and Zeytoonli [93] Iran

Snedden et al. [14]

EUA

2164. Both sexes. Mean: 19,7 years

1350. Both sexes. 17-40 years (Mean: $22.8 \pm 1.3)$

374. Both sexes. Mean: 22.4 years

Vo et al. [94]

Vietnam

712. Both sexes. $19-35$ years
To check for any significant differences in perceived QoL, specifically aspects of a physical nature, among volunteers who are more physically active and those less physically active in a university community

Cross-sectional To examine the relationships between socio-economic status, health promoting lifestyles, and QoL among Chinese Nursing students

Cross-sectional To investigate the relationships between different levels of PA (walking, moderate-intensity activity, vigorous-intensity activity) and HRQoL in a population of male and female University students

Cross-sectional To examine the associations of PA and sedentary behavior with perceived QoL in college students in Venezuela

Cross-sectional To assess the relationship between the PA level and HRQoL of college students

Cross-sectional To explore the relation between PA, sedentary behavior, and the subjective and objective indicators of QoL as well as life satisfaction among university students, whose education is related to different dimensions on health

Cross-sectional To determine the relationship between PA in work, transport, domestic and leisure-time domains and HRQoL among university students

Cross-sectional To estimate HRQoL among students of University of Belgrade (Serbia) and its associations with socio-demographic factors, habits of life, and depression status

Cross-sectional To evaluate the association between leisure-time PA and QoL in medical students

Cross-sectional To investigate the lifestyle, QoL, and PA barriers among female students of Kerman University of Medical Sciences, Iran

Cross-sectional To examine and compare the role of self-assessed sport and PA involvement on HRQoL among undergraduate student-athletes and general undergraduate college students

Cross-sectional To obtain an in-depth understanding of the QoL of medical students in southern Vietnam 
Table 1 (continued)

\begin{tabular}{|c|c|c|c|c|}
\hline Author/year & Country & Sample (n. sex. age) & Study design & Aim of the study \\
\hline Yildirim and Bayrak [80] & Turkey & 1057. Both sexes. 19-27 years & Cross-sectional & $\begin{array}{l}\text { To evaluate the participation of } \\
\text { university students in PA based on } \\
\text { sport and the effects of QoL on the } \\
\text { students' academic achievement and } \\
\text { socialization }\end{array}$ \\
\hline Zhang et al. [75] & EUA & 325. Both sexes. Mean: 21.4 years & Cross-sectional & $\begin{array}{l}\text { To examine the relationships among } 2 \\
\text { X } 2 \text { achievement goal orientations, } \\
\text { PA, and HRQo L in college students }\end{array}$ \\
\hline Zhang et al. [76] & EUA & 235. F. Mean: 21.0 years & Cross-sectional & $\begin{array}{l}\text { To examine the influences of individual } \\
\text { (e.g., self-efficacy, enjoyment), social } \\
\text { (e.g., family and friend support), and } \\
\text { physical environmental factors (e.g., } \\
\text { crime safety) on college women's PA } \\
\text { and HRQoL }\end{array}$ \\
\hline
\end{tabular}

$N R$ not reported. $F$ female, $Q o L$ quality of life; $P A$ physical activity; $S D S$ sports department; $O D S$ others departments; $H R Q L L$ health related quality of life; $M V P A$ moderate/vigorous physical activity; $B M I$ body max index; $F C$ functional capacity

met to agree to resolve the differences, without the need for the participation of a third researcher (Appendix 3).

Of the 8 parameters evaluated in the 30 selected studies, four had only "yes" answers: Exposure measured in a valid and reliable way; Objective criteria and standard for measurement; Results measured in a valid and reliable way; Appropriate statistical analysis. Among the studies, seven $[13,14,74,75,77,81,85]$ met all the parameters evaluated (Fig. 2).

\section{Results of individual studies}

Tables 2 and 3 show the results of the relationship between physical activity and quality of life in university students, showing the various instruments used to evaluate the variables of interest, types of statistical tests used; the adjustment variables and the main outcomes found.
Among the selected studies, the most used instruments to assess the quality of life of the university population were the Quality of Life Questionnaire-short version (WHOQOL-BREF), used by nine studies [70, 71, 78, 79, 81-84, 95] and the Medical Outcomes Study 36-Item Short-Form Health Survey (SF-36), also used by nine articles [12, 75, 80, 85, 87, 90, 91, 93].

The International Physical Activity Questionnaire (IPAQ) was the most used instrument to assess physical activity among university students. It was used by 14 of the 30 studies evaluated $[13,70,73,76,78-80,83$, $85-87,89,90,92]$. The other instruments used to assess quality of life (QOL) and physical activity (PA) and the score obtained in each one are presented in more detail in Table 2.

Table 3 shows the type of statistical test used (association or correlation), in addition to the adjustment variables. As
Fig. 2 Risk of bias in the included studies (The Joanna Briggs Institute Critical Appraisal Checklist for Case Series)

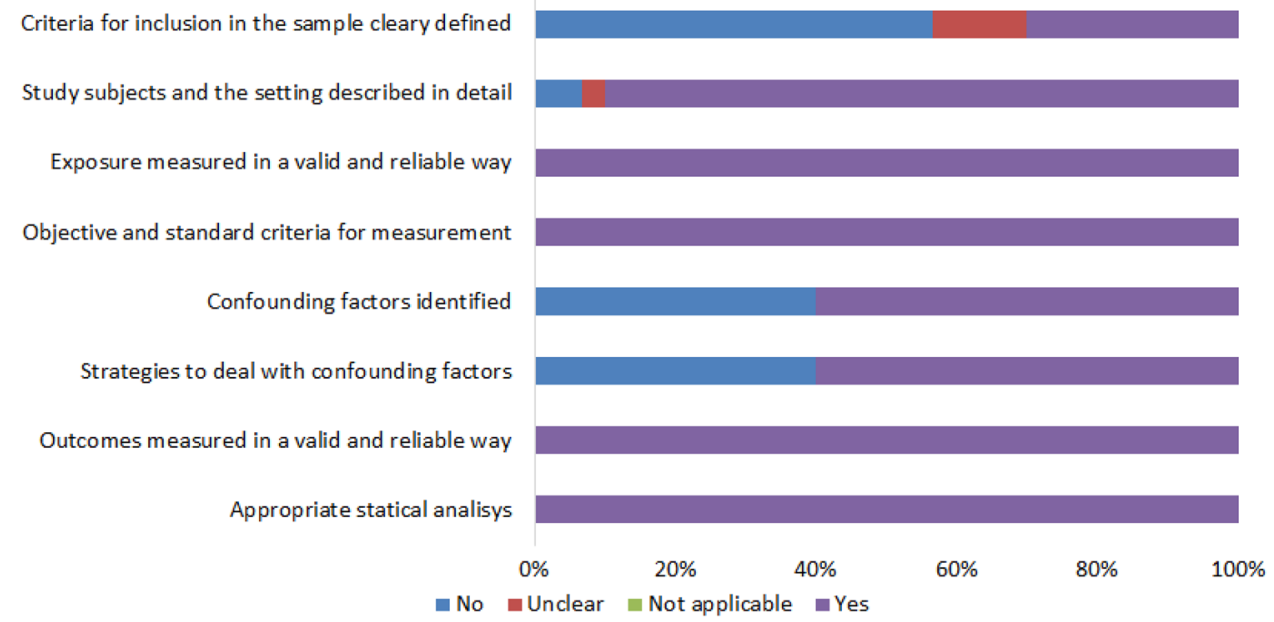




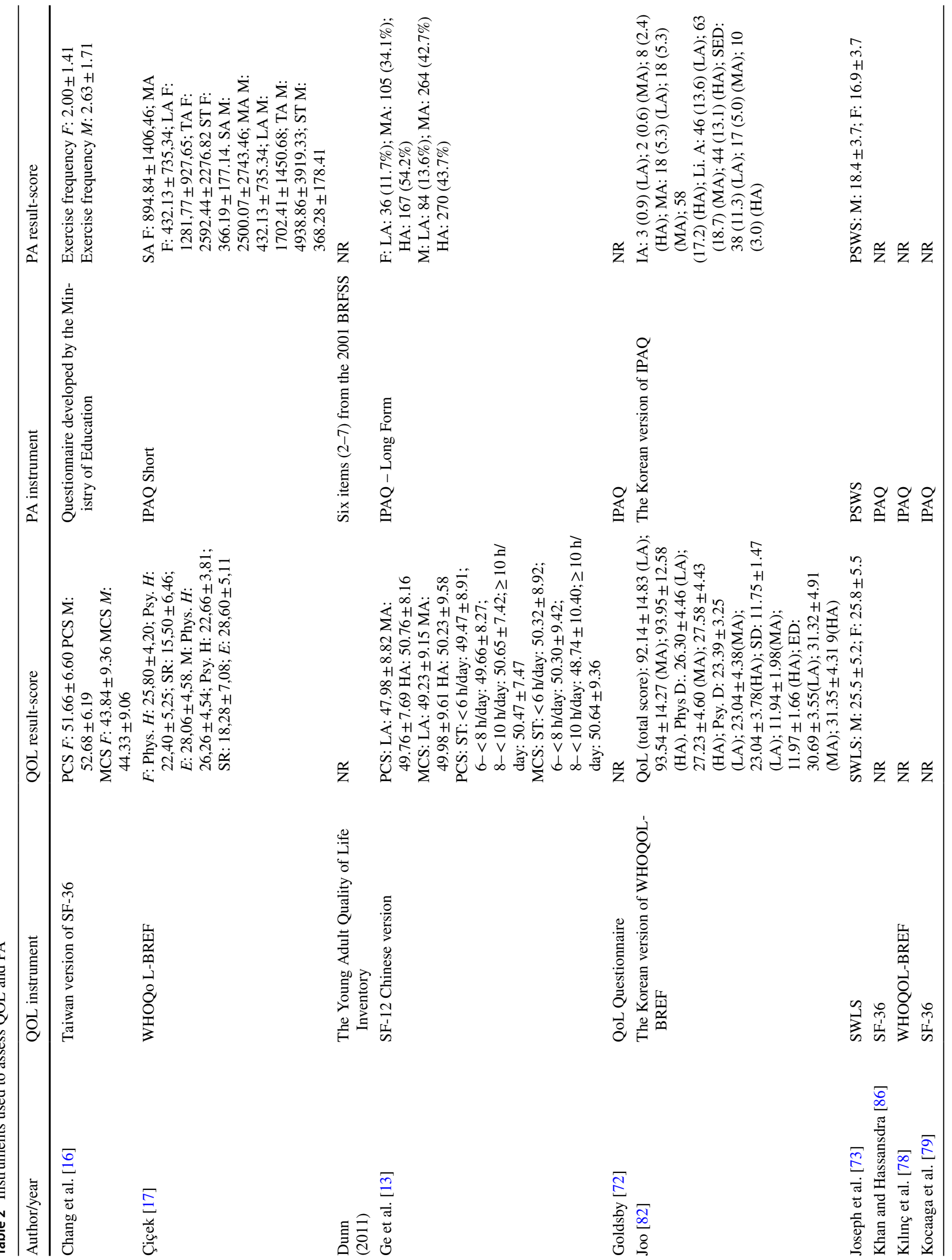




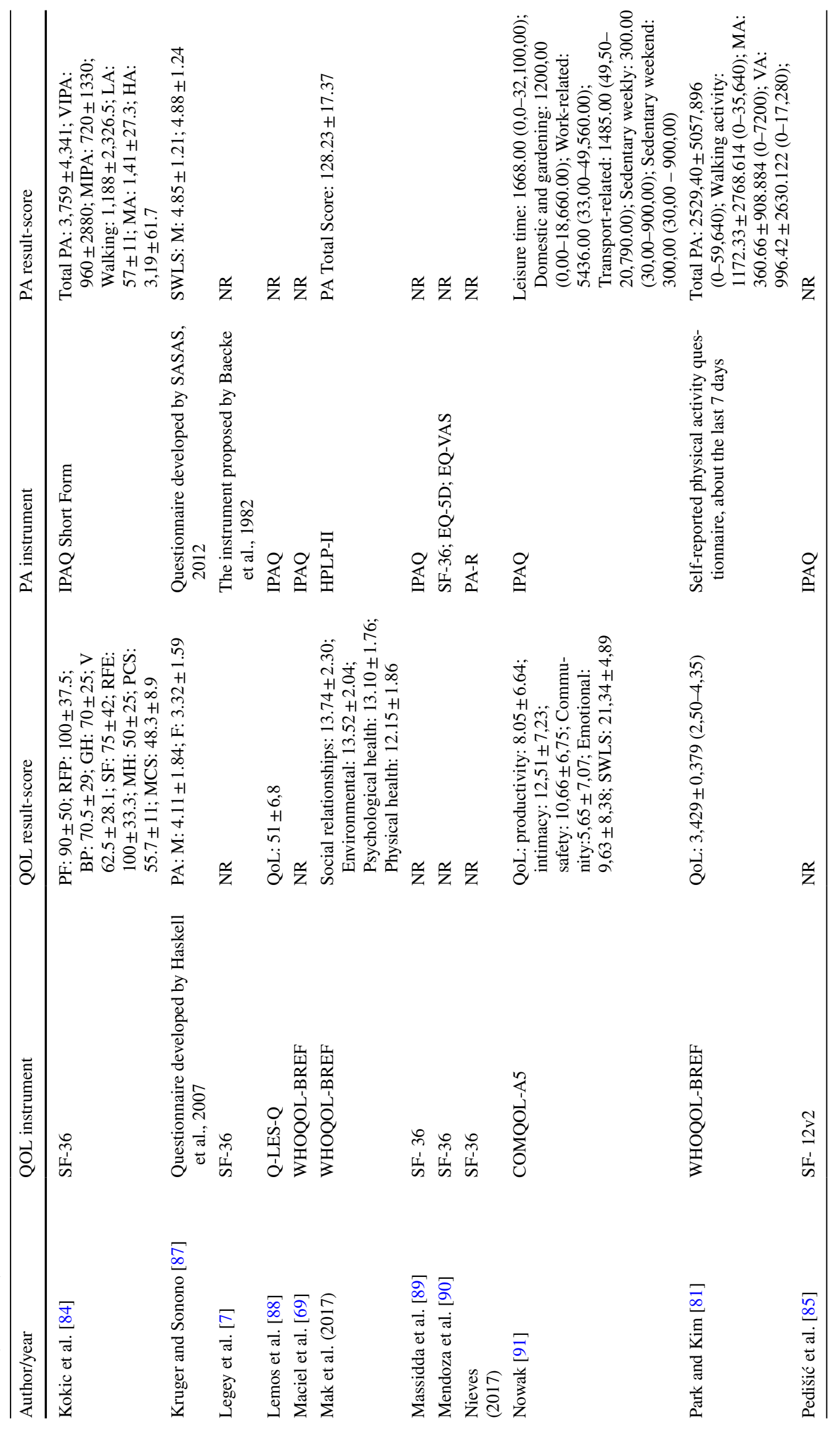




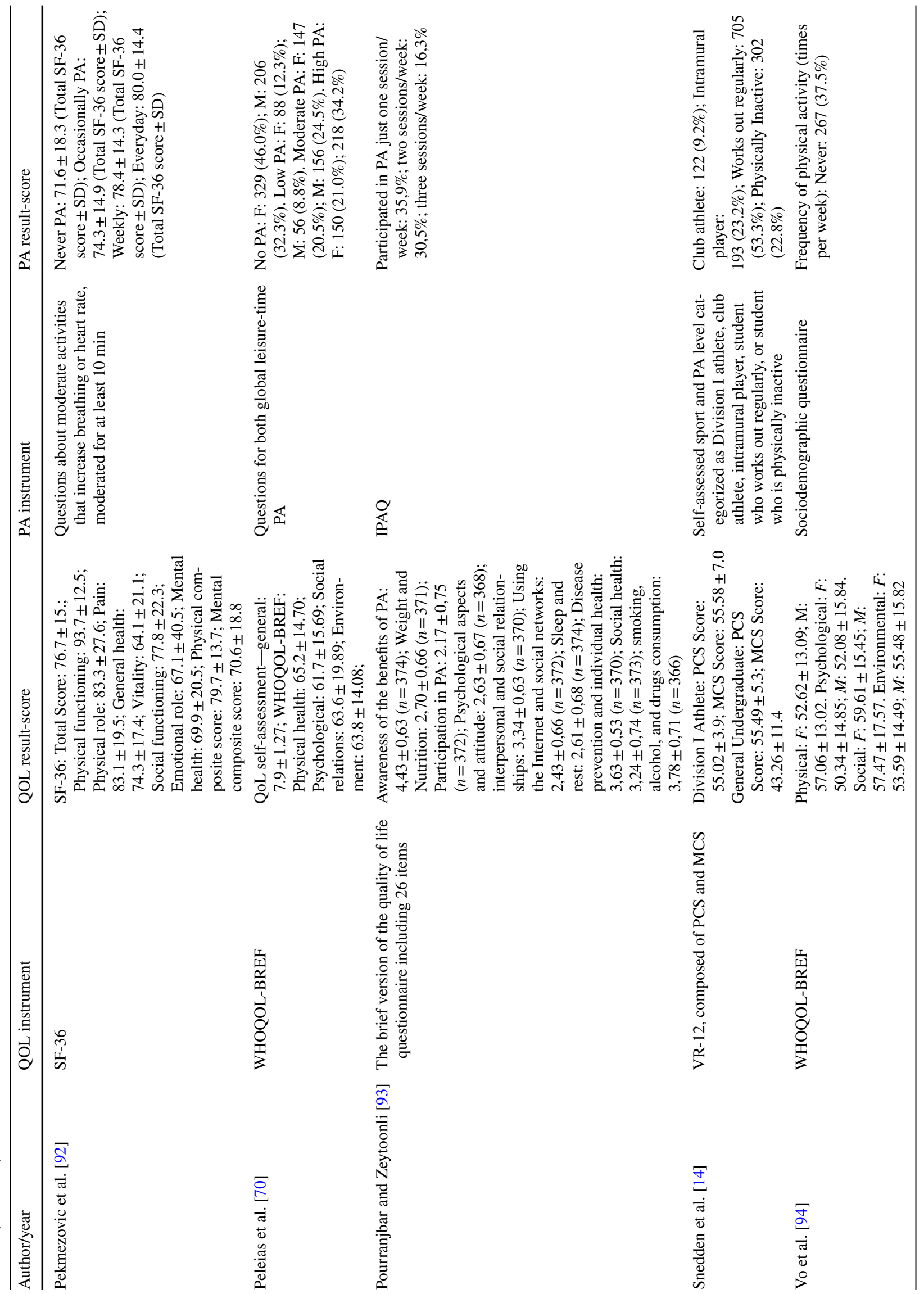




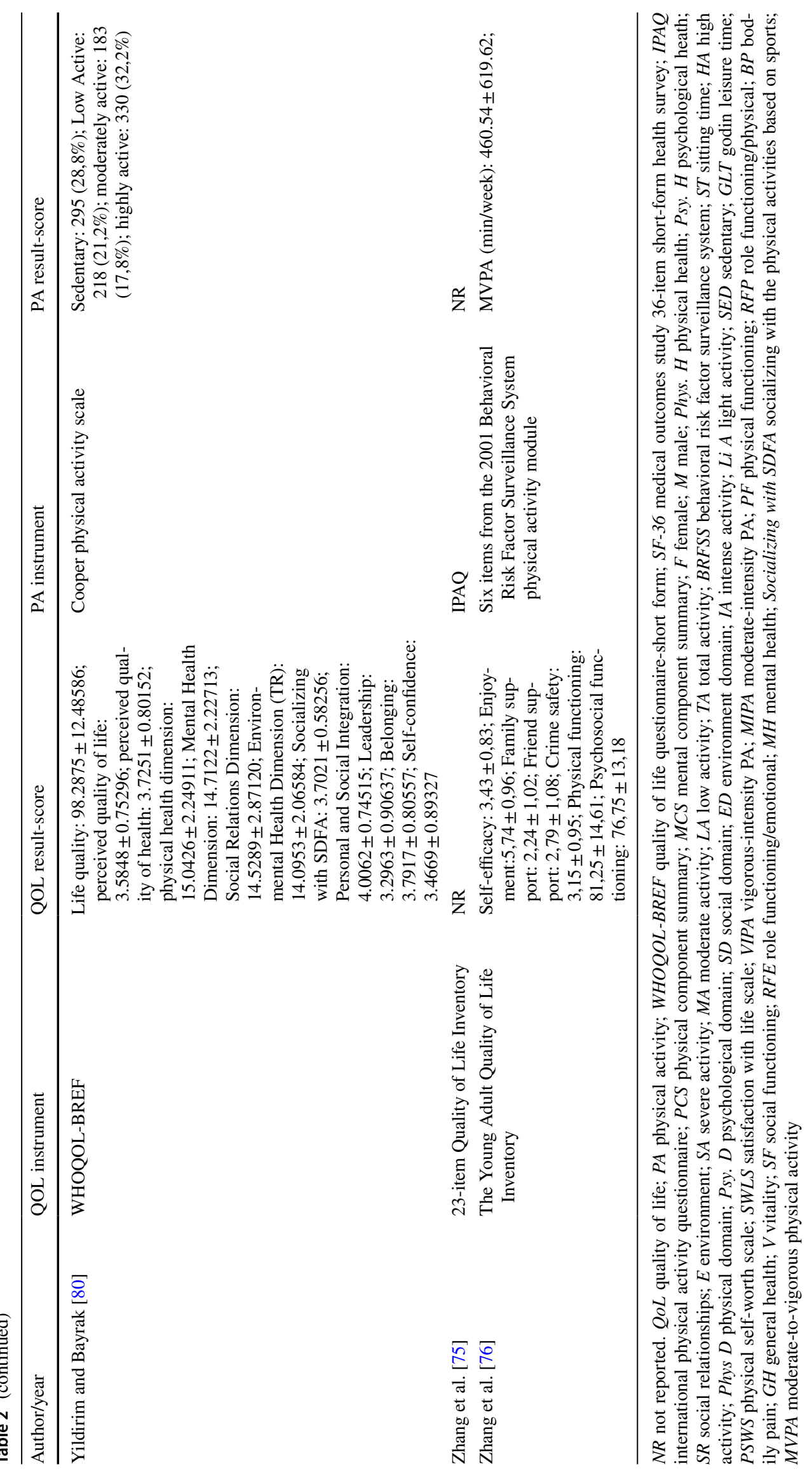




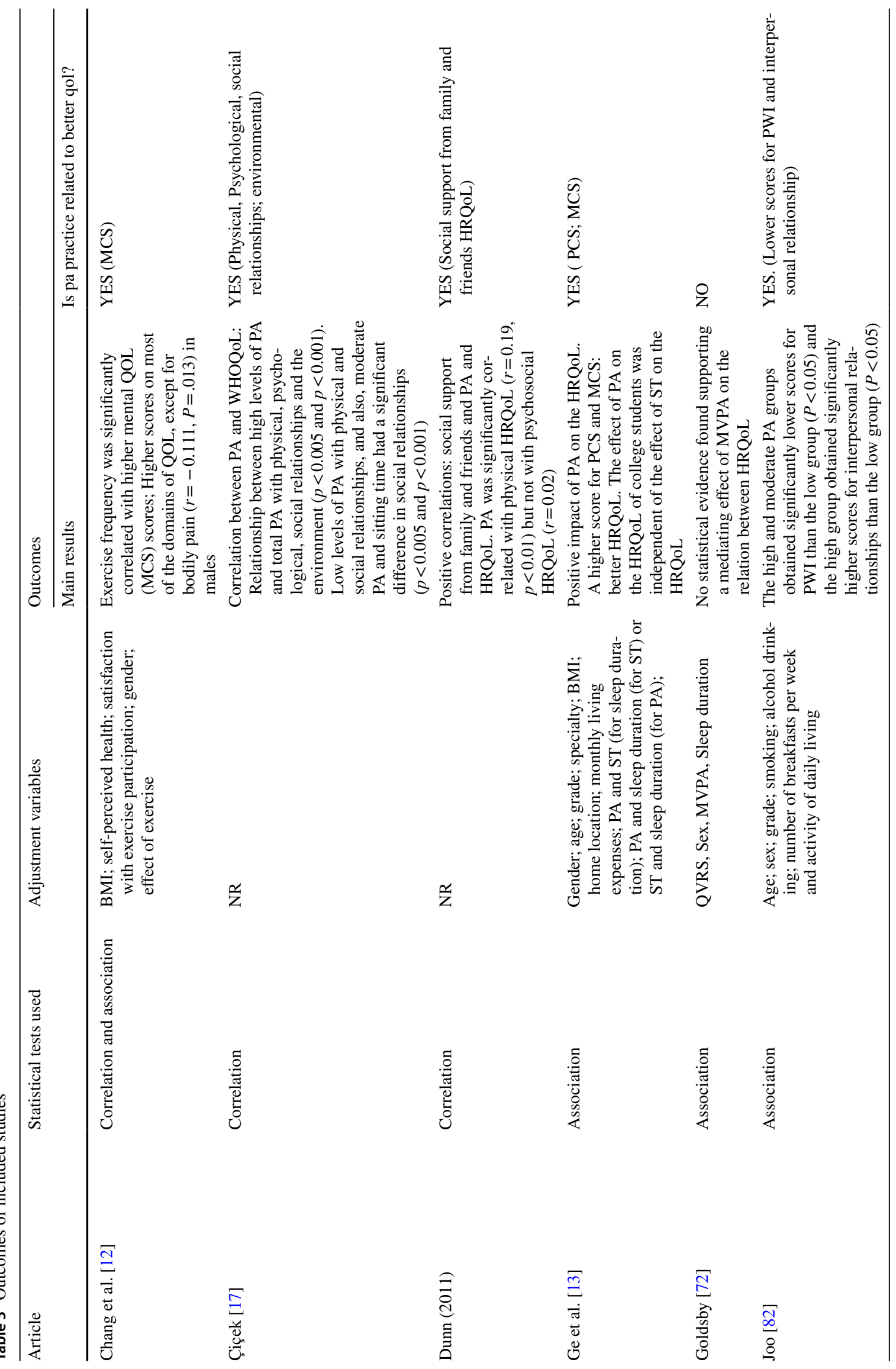




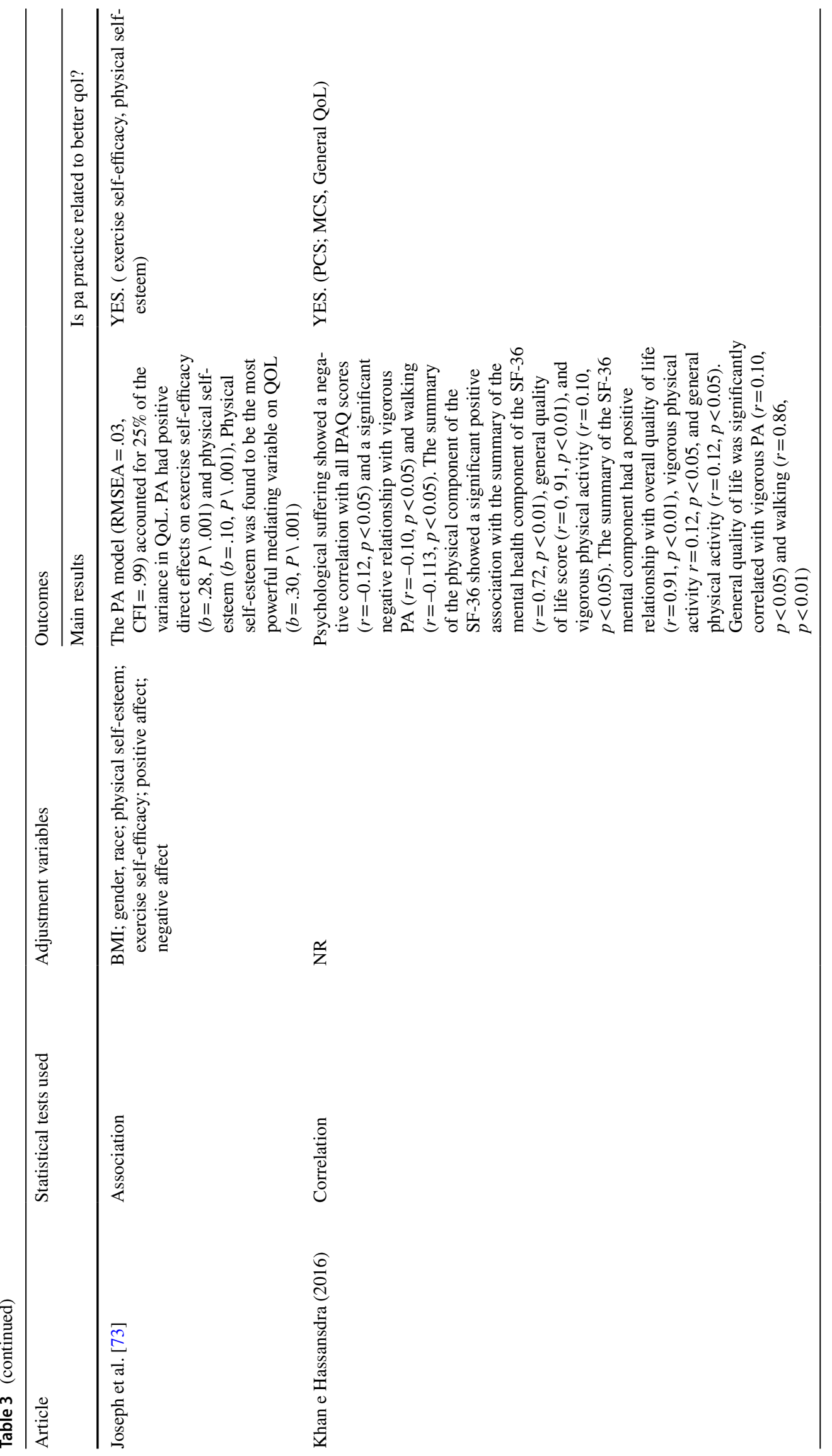




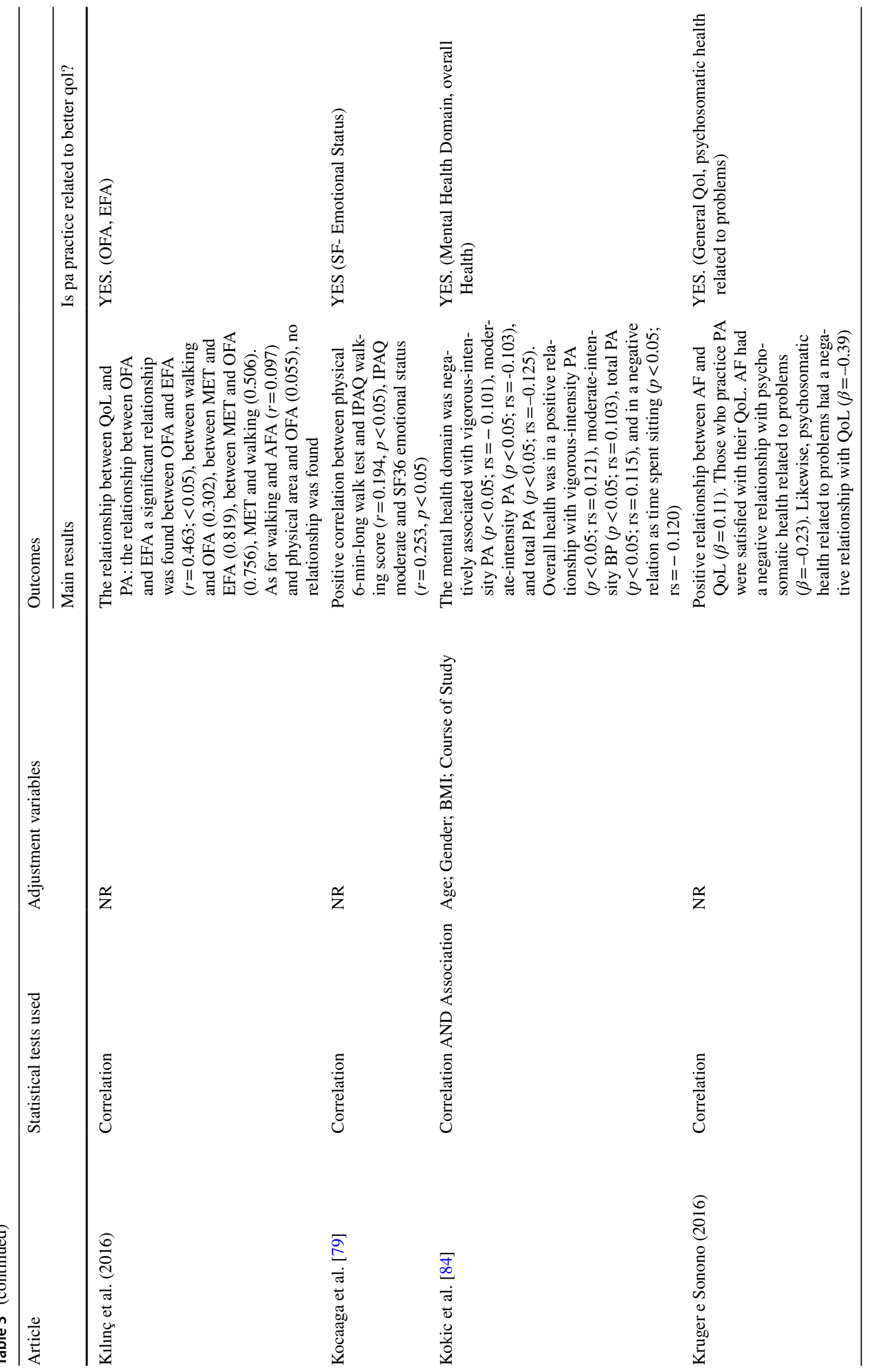




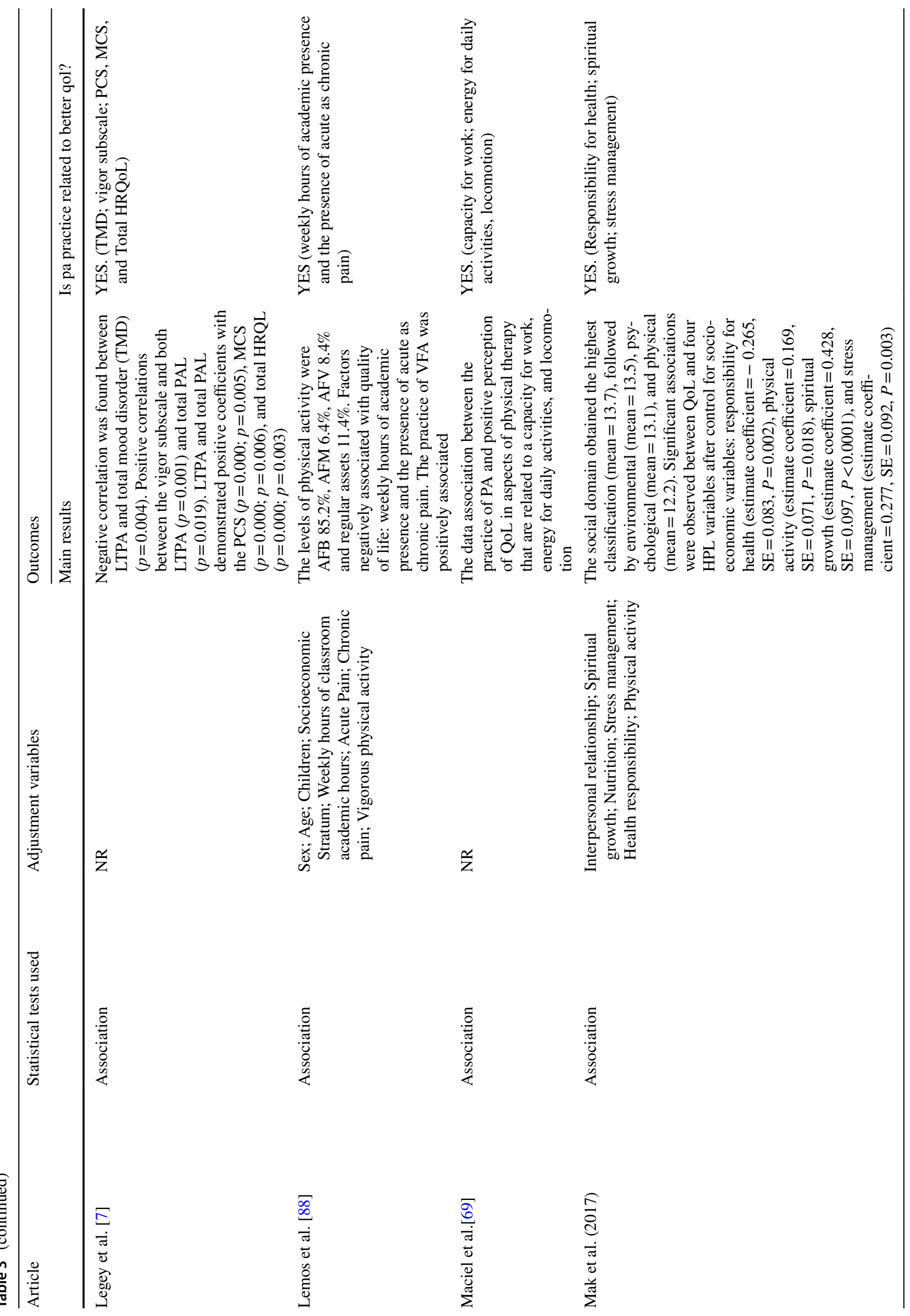




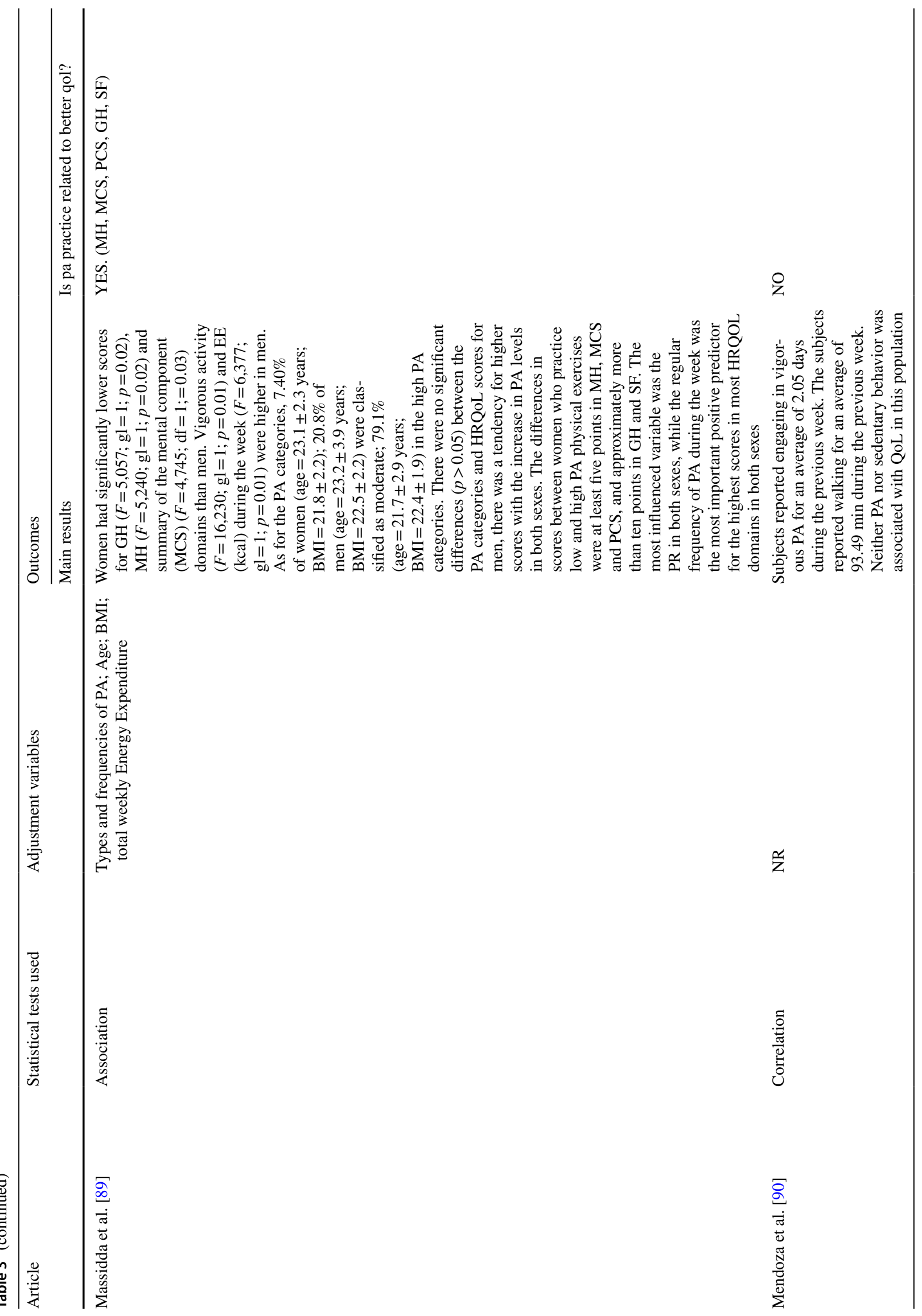




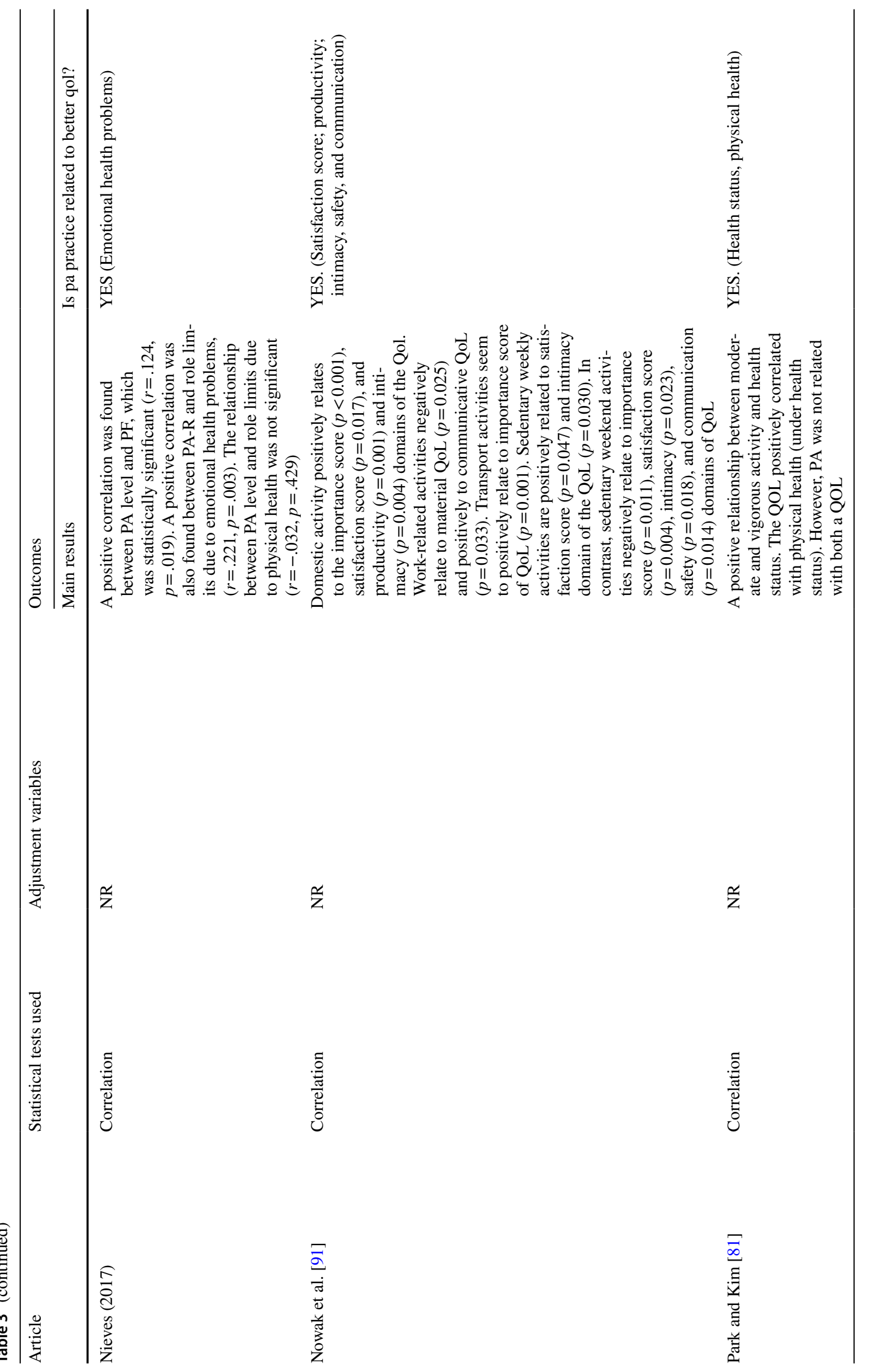




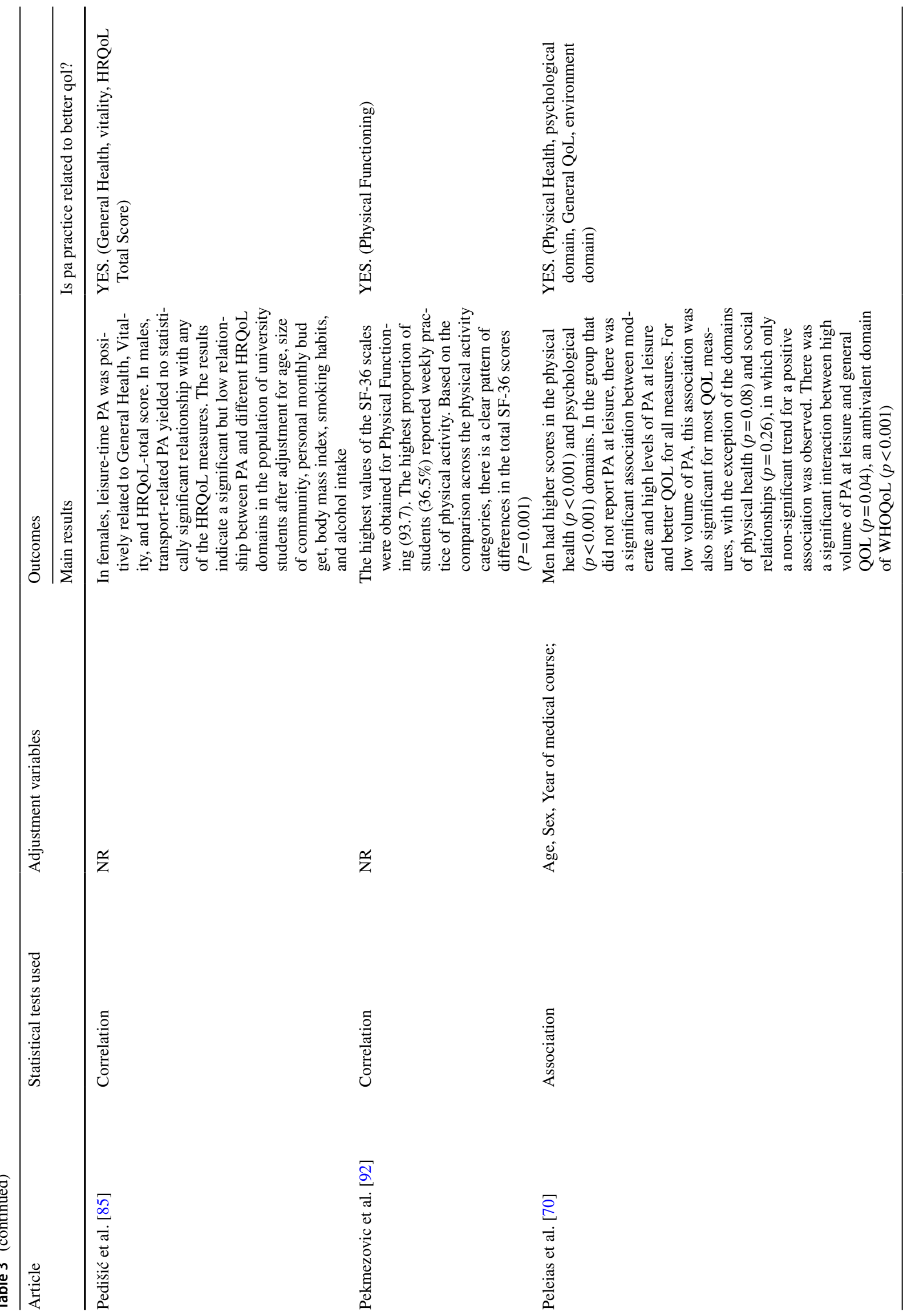




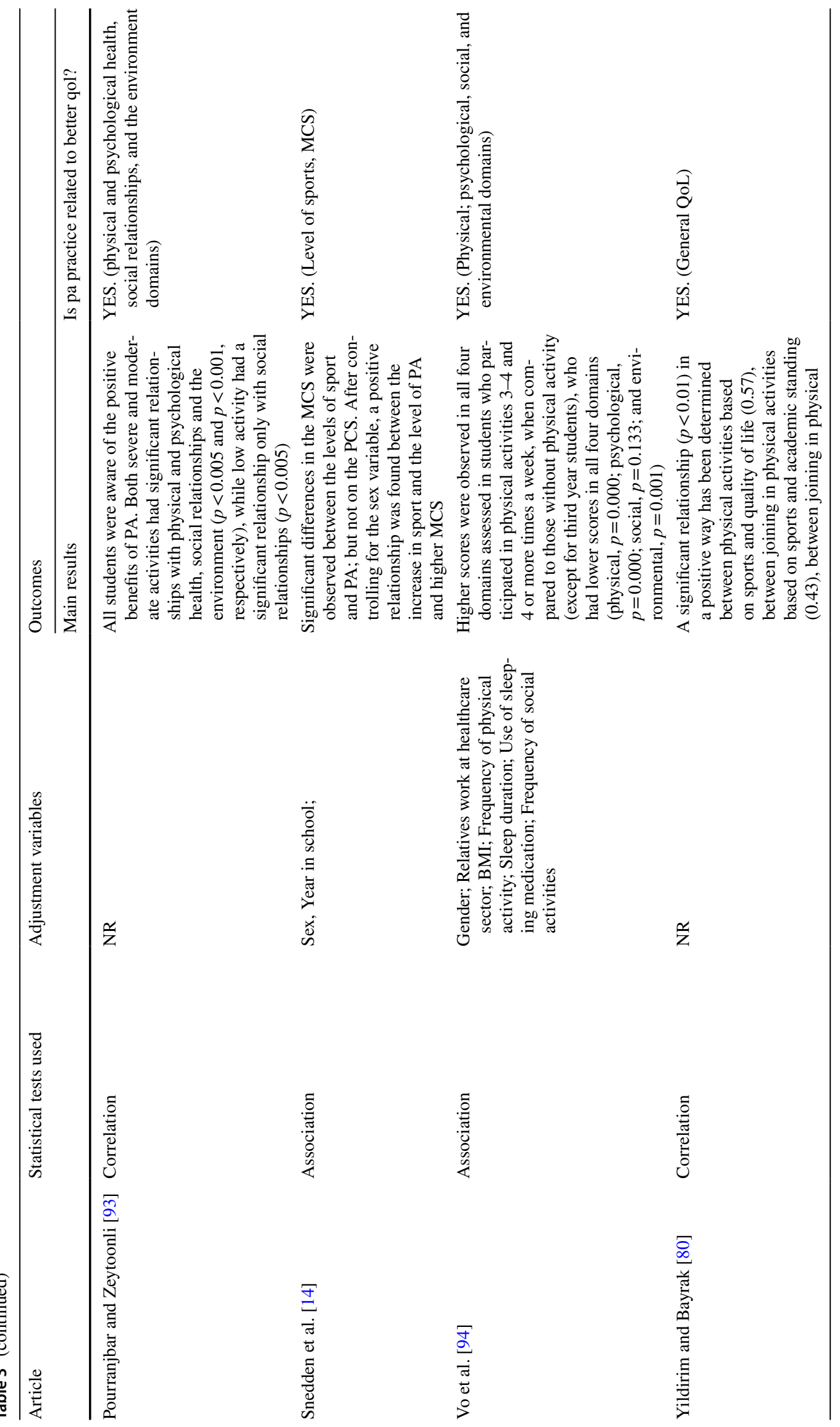




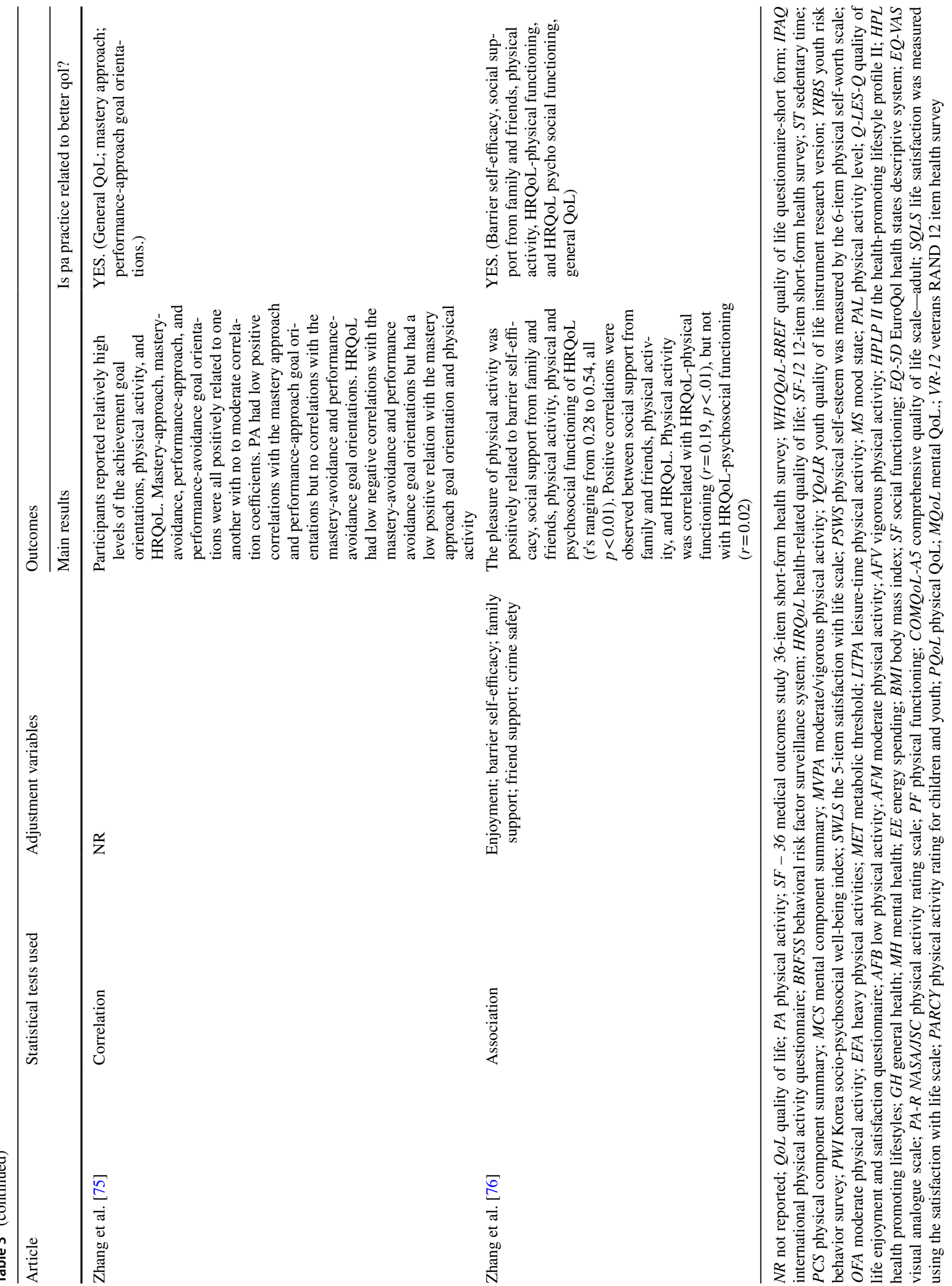


well as the main results, and the answers to the question "IS PA PRACTICE RELATED TO THE BEST QOL?".

In all studies, the practice of physical activity by university students was related to the improvement of their quality of life, in at least one assessed domain. Chang and collaborators (2016) [12] found in their results that a higher frequency of physical exercises correlated with higher Mental Component Summary (MCS) scores.

GE and collaborators (2019) [13] and SNEDDEN and collaborators (2019) [14], also found positive results between physical activity and Physical Component Summary (PCS) and Mental Component Summary (MCS). Their results found that a higher score for PCS and MCS indicated a better Health Related Quality of Life (HRQOL) and a positive relationship between increased sport and PA level and greater MCS, respectively. The other results are presented in more detail in Table 2.

\section{Summary measures and meta-analysis}

The analyzed data were divided into subgroups, according to the common outcomes of the selected articles. They were separated into seven subgroups according to quality of life: Physical Health; Mental health; Social relationships; Environment; Vitality; Pain; General (AF vs QV).

A meta-analysis was performed for each item of quality of life mentioned above. Due to the lack of data in the articles, 22 were included. Weak but significant correlations were found.

The correlation between physical activity and the physical health domain was 0.16 (95\% CI: $\left.0.110 .22 ; I^{2}=99.96 \%\right)$ (Fig. 3); between physical activity and mental health was 0.14 (95\% CI: $0.07-0.20 ; I^{2}=99.97 \%$ ) (Fig. 4); physical activity and social relations: 0.24 (95\% CI 0.08-0.38; $I^{2}=99.99 \%$ ) (Fig. 5); physical activity and the environmental domain: 0.23 (95\% CI 0.14-0.32; $I^{2}=99.90 \%$ ) (Fig. 6); physical activity and vitality: 0.17 (95\% CI $0.15-0.20$; $\left.I^{2}=99.49 \%\right)$ (Fig. 7) physical activity and pain: $0.02(95 \%$ CI -0.02 to $0.12 ; I^{2}=99.96 \%$ ) (Fig. 8) and correlation between physical activity and overall quality of life: 0.21 (95\% CI 0.08-0.34; $I^{2}=99.99 \%$ ) (Fig. 9). An association of $\beta=0.60\left(95 \%\right.$ CI $\left.0.25-0.95 ; I^{2}=85.61 \%\right)$ was found between physical activity and general quality of life (Fig. 10).

\section{Discussion}

This review assessed the relationship between physical activity and quality of life in college students. Our overall results showed weak but positive relationships and associations between PA practice on QoL of these students in several countries around the world. These results underline the importance of encouraging physical activity through policies and actions targeting this audience, and also encouraging the use of universities/faculties themselves, as many of these

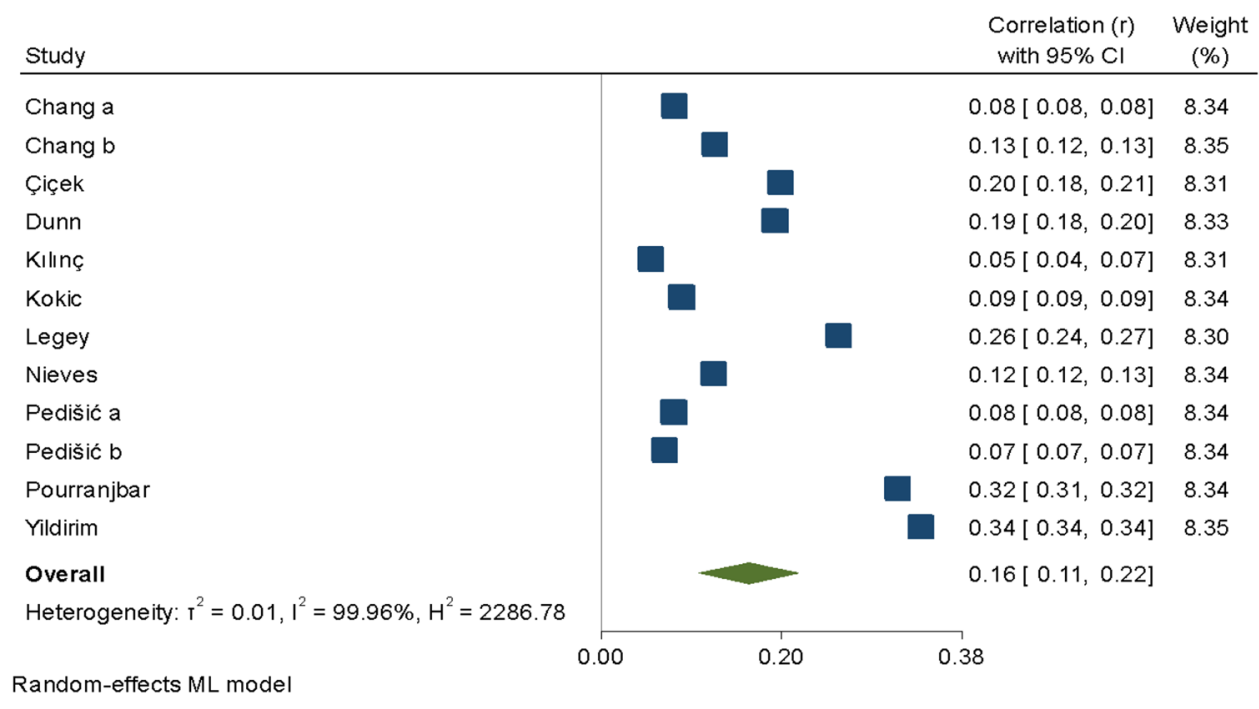

Fig. 3 Correlation between physical activity (PA) and physical domain. Chang a: Exercise Frequency X Physical Component Summary (PCS) in male; Chang b: Exercise Frequency X PCS in female; Çiçek: Total Activity X Physical Health; Dunn: PA X Physical health-related quality of life; Kilinç: Moderate Physical Activity (OFA) X Physical area; Kokic: "My level of PA is adequate" X
PCS; Legey: Physical Activity Level (PAL) X Physical Capacity; Nieves: PAL X Physical Functioning; Pedisic a:Total PA X Physical functioning in female; Pedisic b: Total PA X Physical functioning in male; Pourranjbar: High PA Level X Physical Health; Yildirim: Sports-based physical activity and socialization X QOL ( Physical Health) 


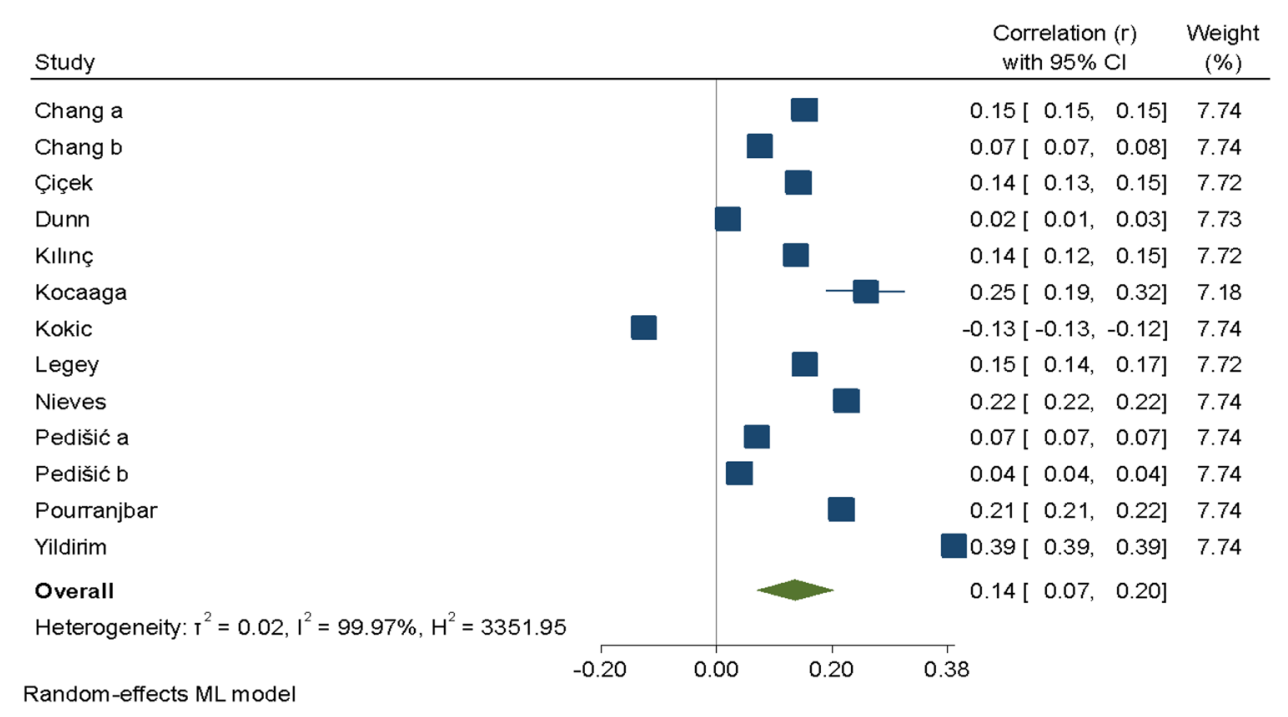

Fig. 4 Correlation between physical activity and mental domain. Chang a: Exercise Frequency $X$ Mental Component Summary (MCS) in male; Chang b: Exercise Frequency X Mental Health in female; Çiçek: Severe Activity X Psychological Health; Dunn: PA $X$ Psychosocial health-related quality of life; Kilinç: Heavy physical activities(EFA) X Psychological Area; Kocaaga: IPAQ moderate X SF36 Emotional Status; Kokic: Total PA X Mental health; Legey:
PAL X Emotional Aspect; Nieves: Physical Activity Rating Scal (PA-R) X Role limits due to emotional problems; Pedisic a: Total PA X Mental Health in female; Pedisic b: Total PA X Mental Health in male; Pourranjbar: Moderate PA Level X Psycological Health Yildirim: Sports-based physical activity and socialization X QoL ( Mental Health)
Fig. 5 Correlation between physical activity and social relationships domain. Chang a: Exercise Frequency X Social functioning (SF) in male; Chang b: Exercise Frequency $X$ Social functioning $(\mathrm{SF})$ in female; Çiçek: Total Activity X Social Relationships; Kilinç: EFA X Social Domain; Legey: PAL X Social Aspect; Pedisic a: Total PA X Social functioning in female; Pedisic b:: Total $\mathrm{PA} X$ Social functioning in male; Pourranjbar: High PA Level X Social Relationships; Yildirim: Sports-based physical activity and socialization $\mathrm{X}$ QOL (Social Relationships)

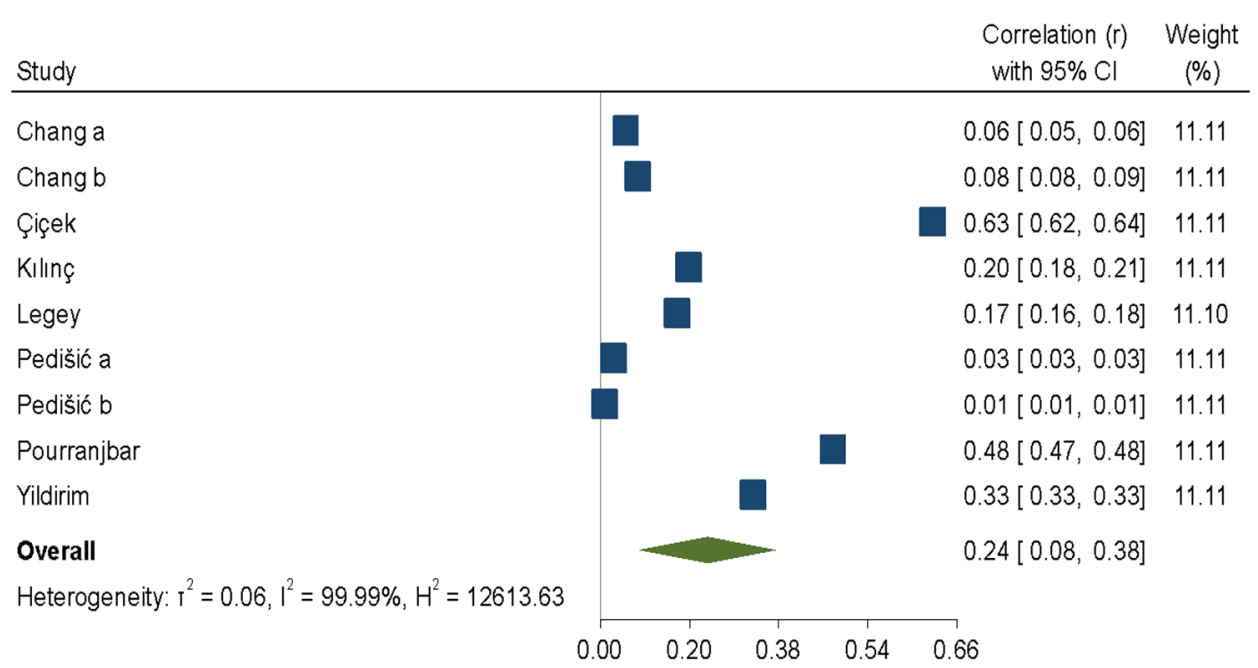

Random-effects ML model institutions have adequate physical space and trained professionals or academics for this type of activity [96-98].

The results of the individual studies showed that students with better levels of PA had better HRQOL scores. The benefits of PA are well known and can directly affect QoL: it helps in the prevention and treatment of chronic diseases; it positively influences sleep quality, physical and mental health, stress and anxiety; it favors social relationships; it helps motor balance; among many others [10, 99]. These findings are in agreement with other previous systematic reviews that have also evaluated the relationship between PA and QL in adults in general [100, 101]; children and adolescents [102] and the elderly [103], showing the positive influence of this relationship and other populations.

Our meta-analysis revealed significant associations between PA and global QoL. And significant correlations between PA and global QoL, and PA and the domains: physical, mental, social relations, environment, vitality in higher education students. High heterogeneity was found in all analyses, which may be due to methodological causes, since the 

physical activity (PA and environment domain. Çiçek: Total Activity X Environment; Kilinç: EFA X Environmental area; Pourranjbar: High PA Level X Environment; Yildirim: Sportsbased physical activity and socialization X Environmental Health the vitality domain (VT) and physical activity (PA). Chang a: Exercise Frequency X VT in male; Chang b: Exercise Frequency X VT in female; Kokic: Total PA X VT; Legey: Physical Activity Level X VT; Pedisic a: PA total X VT in female; Pedisic b: PA total X $\mathrm{VT}$ in male
Fig. 6 Correlation between

Fig. 7 Correlation between

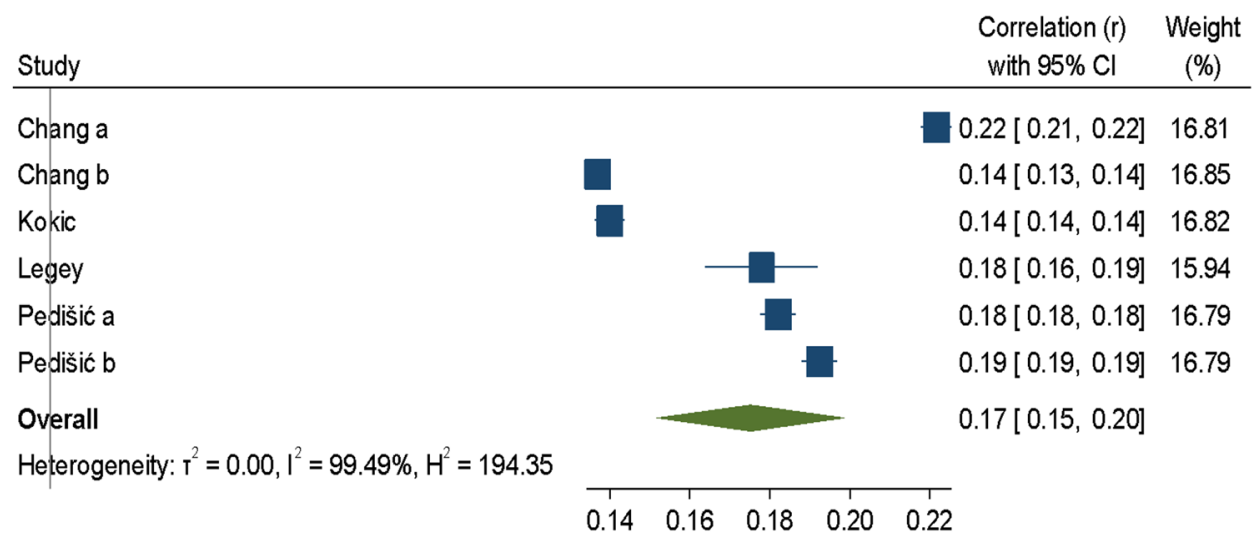

Random-effects ML model

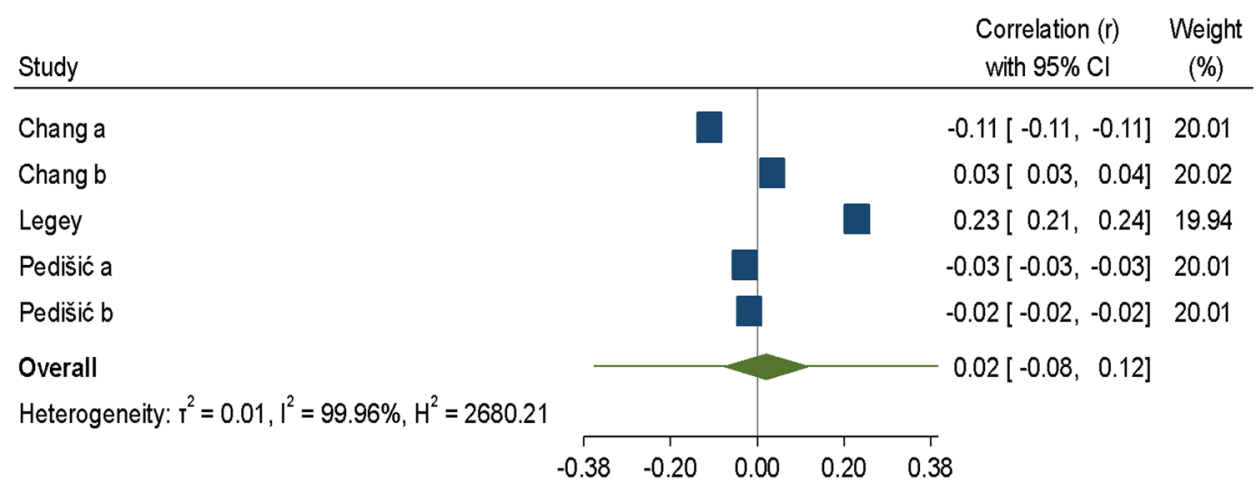

Random-effects ML model

Fig. 8 Correlation between physical activity and pain domain. Chang a: Exercise Frequency X Bodily pain (BP) in male; Chang b: Exercise Frequency X Bodily pain (BP) in female; Legey: PAL X Pain; Pedisic a: Total PA X Bodily pain in female; Pedisic b: Total PA X Bodily pain in male

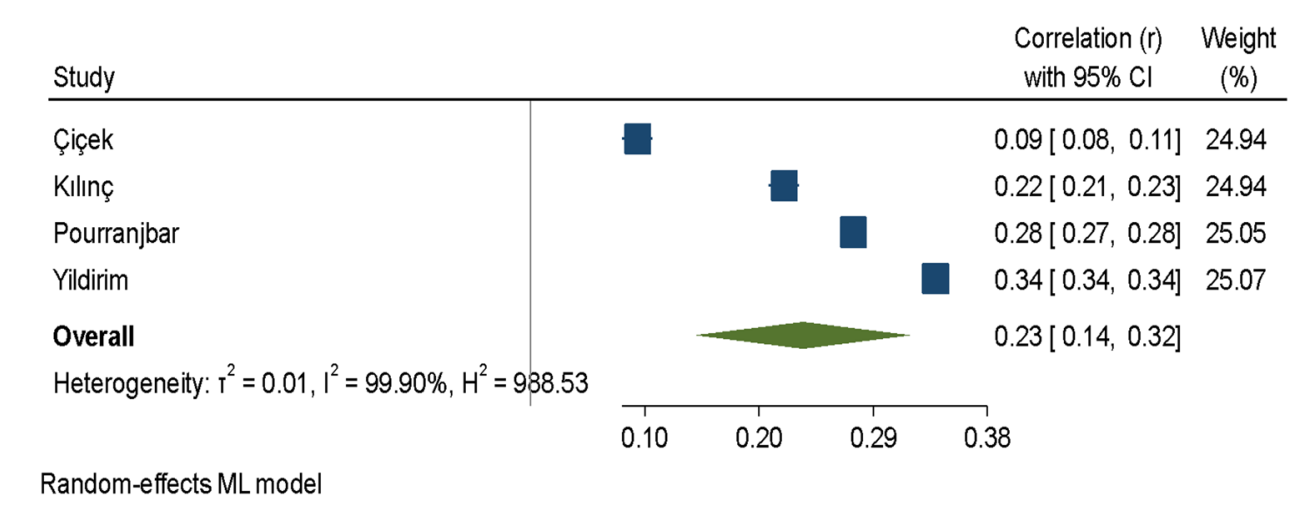


Fig. 9 Correlation between physical activity and general quality of life. Ji- Yeon (Park): Total physical activity $\mathrm{X}$ Quality of Life (QoL); Khan: Overall Physical Activity X QoL; Kilinç: Physical Activity X QoL; Kruger: PA X QoL; Legey: Physical Activity Level (PAL)X HRQoL Total; Yildirim: Physical activity based on sports and socializing $X$ QoL; Zhang: PA X Masteryapproach goal orientation

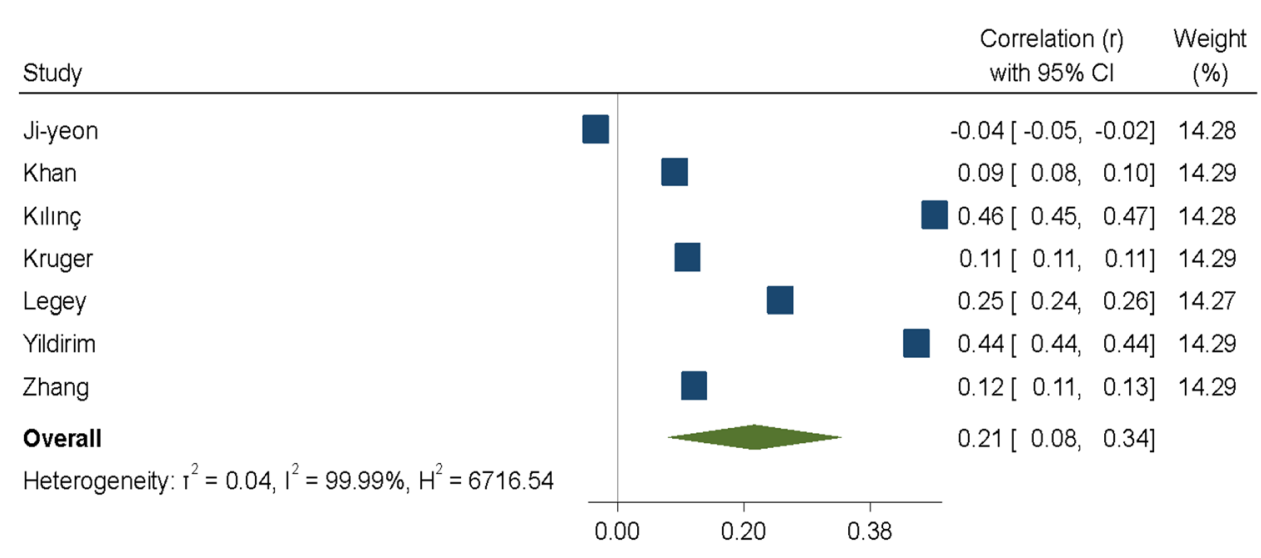

Random-effects ML model
Fig. 10 Association between physical activity and general quality of life. Goldsby: Moderate-vigorous physical activity (MVPA) X Health Related Quality of Life; Lemos: Vigorous physical activity X QoL; Mak: PA (HPL) X QoL; Peleias: High PA X QoL selfassessment-general total

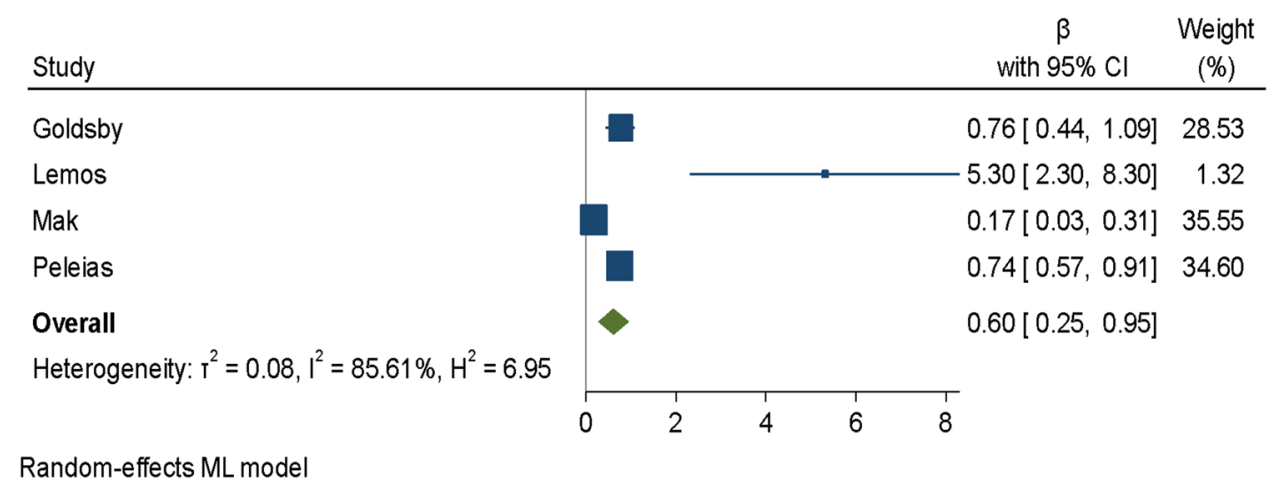

the predictors of a positive mental health status $(\beta=0.032$; 95\% CI 0.016-0.048; $p<0.001)$. These findings emphasize the importance of an active life during all stages, but especially, during higher education, where these individuals undergo significant changes in their lives. Evidence points out that regular physical activity brings benefits for functioning and physical fitness, is able to reduce stress, positively influence self-esteem and cognitive functioning, which are essential elements for good mental health [107, 108].

Wu et al. (2015) [109] found that, among 4747 Chinese university students, high screen time ( $>2$ h/day) was positively correlated with anxiety, depression, psychopathological symptoms, and poor sleep quality. In addition, there were progressive increases in protective effects against depression, psychopathological symptoms, and poor sleep quality with increasing levels of physical activity. In addition, the authors found that participants with high PA and low screen time had the lowest risk of psychopathological symptoms $(\mathrm{OR}=0.46,95 \%$ CI $0.32-0.67)$ and poor sleep quality compared to the other groups ( $\mathrm{OR}=0.50,95 \%$ CI $0.30-0.82)$.

Similarly, another study conducted with 617 Indian university students showed that the participants' physical activity levels (moderate and high) were inversely associated with anxiety scores $(\mathrm{OR}=0.16$ and $0.96 ; p=0.001)$ and of depression $(\mathrm{OR}=0.11$ and $0.96 ; p=0.001)$. Also, poor sleep quality was positively associated with anxiety $(\mathrm{OR}=1.38)$ and depression $\mathrm{OR}=1.58(p=0.001)$ [110]. These results suggest that greater sedentary behavior, represented by screen time, and lower PA level are related to the development of anxiety, depression, psychopathological symptoms, and poorer sleep quality. These are factors that can influence the quality of life of individuals.

In our results, positive correlations were also found between PA and vitality (0.17. 95\% CI 0.15-0.20; $I^{2}=99.49 \%$ ). Vitality is one of the domains of QL, it is used in determining Mental Component Summary (MCS) and Physical Component Summary (PCS) scores [111]. Corroborating our results, even though with another population, Puetz (2006) [112], conducted a literature review, where he searched for epidemiological studies that examined the association between PA and feelings of energy and fatigue in individuals with a mean age of $49.4 \pm 10$ years; and in his results he found that higher risks of low vitality were associated with less active lifestyles.

It is important to consider that with the COVID-19 pandemic, caused by (SARS)-CoV-2, it caused negative effects in the general population worldwide. Recent studies show that physical activity can help improve and maintain the mental health of individuals, even in periods of social isolation. Ozdemir et al. (2020) [113] carried out a study eight 
weeks after the announcement of the first case in Turkey in which they evaluated 2301 adults aged 20 to 75 . The authors found that only $6.9 \%$ of the sample were physically active, there was a positive relationship between physical activity levels and quality of life, while there was a negative relationship between levels of physical activity, depression, and anxiety $(p<0.05)$. Also, when physically active and inactive participants were compared, a difference was observed for the variables of general health status and physical and psychological health status $(p<0.05)$.

Another study carried out with 645 Chinese adults showed that there was a reduction in the practice of PA during the pandemic, whereas before, $49.3 \%$ performed some PA from 2 to 4 times a week and $26.1 \%$ more than five times a week. However, $64.8 \%$ of participants engaged in little physical activity (i.e., less than $600 \mathrm{MET}$-min/week) during the COVID-19 pandemic. Only $18.0 \%$ and $17.2 \%$, respectively, of the participants practiced moderate and high levels of physical activity. Furthermore, the results indicated that there was an increase in the average time of sedentary lifestyle from the pre-COVID-19 period $(M=5.4$, $\mathrm{SD}=2.9)$ to the COVID-19 pandemic period $(M=5.8$, $\mathrm{SD}=4.6),(t(644)=-2.6, p<0.05)$. In addition, there was a reduction in the scores for the physical and mental components related to quality of life (75.3; $\mathrm{SD}=16.6$ and 66.6; $\mathrm{SD}=19.3$, respectively). Finally, more than half of participants $(53.6 \%)$ reported moderate levels of perceived stress during the COVID-19 pandemic [114].

Considering the university population, the suspension of in-person classes, the longer time at home and the need to adapt to a new model of remote classes may have contributed to the worsening of these individuals' mental health. In addition, social isolation and the closing of gyms may have influenced this population to reduce or discontinue physical activity. In this sense, Gallo et al. (2020) [114] compared the practice of physical activity among university students in Australia and found that there was a reduction in the time spent walking between men and women from 2018/2019 to $2020(p<0.05)$. Also, fewer participants reached "sufficient" levels of activity in 2020, compared to 2018/2019 $(p<0.05)$. These results may highlight the importance of public health strategies designed to encourage the adoption of healthy lifestyle habits in order to improve and maintain health and quality of life at the population level.

It should also be noted that systematic reviews are high quality sources of information; they provide a relevant synthesis of results, covering as many articles as possible to answer the research question. Their sample includes a significant number of people; in a diverse way; bringing representativeness to the population studied. In addition, the cost of its development is low; most often it requires as work the authors' research and writing time, without any additional cost, as with original articles. It is a very useful tool for evidence-based clinical practice, and can be used as a source of research for the development and evaluation of policies, actions and programs in the management of municipalities, states or countries [113, 114].

\section{Study limitations}

One of the limitations of this study was the heterogeneity of the methodologies used in the articles, which were all cross-sectional, making it difficult to carry out other complementary statistical analysis. In addition, many times they were not taken by the authors as being marked as an error (Standard Error, Standard Deviation, Confidence Interval or Variance), and it was also required to perform meta-analyses. As these are only cross-sectional studies, it is not possible to state that physical activity improves quality of life, and further studies are needed, especially of the longitudinal type that allow this monitoring.

Another limitation is due to the fact that studies may have been included or excluded due to the way the instrument was described by the authors of the original articles and, therefore, they were selected according to the terms used in the search strategy of this review. Some examples are original articles that used instruments such as "Satisfaction with Life Scale" or similar and were included even though satisfaction with life was not a search term. As occurred with others who used the SF-36, and do not refer to it as "Quality of life", but rather as health status or similar expressions.

\section{Strengths of the study}

This systematic review was carried out using the most current recommended methods for this type of study. It followed PRISMA [21], and was registered with PROSPERO. In addition, the PRESS [22] checklist was also used. The selection of the studies took place independently and several databases were used in order to achieve a large number of studies. Grey literature was also consulted. When necessary, the authors were contacted in order to obtain answers regarding the articles. There were no studies similar to this one, of systematic review and meta-analysis found in the literature.

\section{Conclusion}

The results of our study showed weak but positive relationships between physical activity and overall quality of life of college students and also between PA and the domains of QoL: physical health, social relationships, mental health, environment and vitality, in this same population. These may alert to the need to increasingly study this population, as they undergo intense changes and behaviors that tend to perpetuate into other life stages, and may also highlight the 
importance of bringing more data to support the development of policies, actions, and programs that benefit these students.

Funding To the Fundação de Amparo à Pesquisa do Estado de Minas Gerais (FAPEMIG, Brazil), for granting the scholarship. To the Coordenação de Aperfeiçoamento de Pessoal de Ensino Superior (CAPES, Brazil) and to the Conselho Nacional de Desenvolvimento Científico e Tecnológico (CNPq, Brazil) for financial support. To the Programa de Pós- Graduação em Ciência da Nutrição (PPGCN/UFV) e to the Universidade Federal de Viçosa.

\section{Declarations}

Conflict of interest There is no conflict of interest regarding the research, authorship, or publication of this article.

Availability of Data and Material Not applicable.

Code Availability Stata Software, version 16, serial number 301606311865

Ethical Approval Not applicable.

Informed Consent Not applicable.

\section{References}

1. Calestine, J., et al. (2017). College student work habits are related to physical activity and fitness. International Journal of Exercise Science, 10(7), 1009-1017.

2. García Hermoso, A., et al. (2017). Reallocating sedentary time to moderate to vigorous physical activity but not to light intensity physical activity is effective to reduce adiposity among youths: a systematic review and meta- analysis. Obesity Reviews, 18(9), 1088-1095. https://doi.org/10.1111/obr.12552

3. Tao, K., et al. (2019). Associations between self-determined motivation, accelerometer-determined physical activity, and quality of life in chinese college students. International Journal of Environmental Research and Public Health, 16(16), 29-41. https://doi.org/10.3390/ijerph16162941

4. World Health Organization (2014). Global status report on noncommunicable diseases. Disponível em: https://apps.who.int/iris/ bitstream/handle/10665/148114/9789241564854_eng.pdf?seque nce $=1$.

5. Silva, S., \& Silva, A. (2010). Physical activity and quality of life. Ciência \& Saúde Coletiva, 15(1), 115-120. https://doi.org/10. 1590/S1413-81232010000100017

6. Centers for Disease Control and Prevention. (2016). Healthrelated quality of life (HRQOL) well-being concepts. Reference from https://www.cdc.gov/hrqol/wellbeing.htm.

7. Legey, S., et al. (2017). Relationship among physical activity level, mood and anxiety states and quality of life in physical education students. Clinical Practice and Epidemiology in Mental Health, 9(13), 82-91. https://doi.org/10.2174/174501790171301 0082

8. Zhao, M., Veeranki, S. P., Magnussen, C. G., \& Xi, B. (2020). Recommended physical activity and all cause and cause specific mortality in US adults: Prospective cohort study. BMJ, 370, 20-31. https://doi.org/10.1136/bmj.m2031
9. Kallio, J., et al. (2020). Changes in physical activity and sedentary time during adolescence: Gender differences during weekdays and weekend days. Scandinavian Journal of Medicine \& Science in Sports, 30, 1265-1275.

10. Lantyer, A. S., et al. (2016). Ansiedade e qualidade de vida entre estudantes universitários ingressantes: Avaliação e intervenção. Revista Brasileira de Terapia Comportamental e Cognitiva, 17(2), 4-19.

11. Esteves, D., et al. (2017). Nível de atividade física e hábitos de vida saudável de universitários portugueses. Revista Iberoamericana de Psicología del Ejercicio y el Deporte, 12 (2), 261-270. https://www.redalyc.org/articulo.oa? $\mathrm{id}=311151242009$.

12. Chang, S. P., et al. (2016). Association between exercise participation and quality of sleep and life among university students in Taiwan. Asia-Pacific Journal of Public Health, 28(4), 356-367. https://doi.org/10.1177/1010539516645160

13. Ge, Y., et al. (2019). Association of physical activity, sedentary time, and sleep duration on the health-related quality of life of college students in Northeast China. Health and Quality of Life Outcomes, 16(1), 124. https://doi.org/10.1186/ s12955-019-1194-x

14. Snedden, T. R., et al. (2019). Sport and physical activity level impacts health-related quality of life among collegiate students. American Journal of Health Promotion, 33(5), 675-682. https:// doi.org/10.1177/0890117118817715

15. Kumar, B., Robinson, R., \& Till, S. (2015). Physical activity and health in adolescence. Clinical Medicine, 15(3), 267-272.

16. Solis, A. C., \& Lotufo-Neto, F. (2019). Predictors of quality of life in Brazilian medical students: A systematic review and meta-analysis. Brazilian Journal of Psychiatry, 41(6), 556-567. https://doi.org/10.1590/1516-4446-2018-0116

17. Seid, E. M. F., \& Zannon, C. M. L. C. (2004). Qualidade de vida e saúde: Aspectos conceituais e metodológicos. Caderno de Saúde Pública, 20(2), 580-588. https://doi.org/10.1590/S0102311 X2004000200027

18. Anversa, A. C., et al. (2018). Qualidade de vida e o cotidiano acadêmico: uma reflexão necessária. Cadernos Brasileiros de Terapia Ocupacional, 26(3), 626-631. https://doi.org/10.4322/ 2526-8910.ctoAO1185

19. Moreira, N. B., Mazzardo, O., Vagetti, G. C., de Oliveira, V., \& de Campos, W. (2019). Qualidade de vida. Revista Brasileira de Educação Física e Esporte, 33(1), 107-114. https://doi.org/10. 11606/issn.1981-4690.v33i1p107-114

20. Guthold, R., Stevens, G. A., Rildey, L. M., \& Bull, F. C. (2019). Global trends in insufficient physical activity among adolescents: A pooled analysis of 298 population-based surveys with 1.6 million participants. The Lancet Child \& Adolescent Health, 4(1), $23-35$.

21. Liberati, A., Altman, D. G., Tetzlaff, J., et al. (2009). The PRISMA statement for reporting systematic reviews and metaanalyses of studies that evaluate health care interventions: Explanation and elaboration. PLoS Medicine. https://doi.org/10.1371/ journal.pmed. 1000100

22. McGowan, J., Sampson, M., Salzwedel, D. M., et al. (2016). PRESS peer review of electronic search strategies: 2015 Guideline statement. Journal of Clinical Epidemiology, 75, 40-46. https://doi.org/10.1016/j.jclinepi.2016.01.021

23. Moola, S., Munn, Z., Tufanaru, C., et al. (2017). The Joanna Briggs Institute Critical Appraisal tools for use in JBI. Systematic Reviews Checklist for Case Series. The Joanna Briggs Institute.

24. Dersimonian, R., \& Laird, N. (1986). Meta-analysis in clinical trials. Controlled Clinical Trials, 7, 177-188.

25. Deeks, J. J., HigginS, J. P. T., Altman, D. G. (2019). (editors). Chapter 10: Analysing data and undertaking meta-analyses. In: Higgins, J. P. T., Thomas, J., Chandler, J., Cumpston, M., Li, 
T., Page, M. J., Welch, V. A. (editors). Cochrane Handbook for Systematic Reviews of Interventions Version 6.0. Cochrane. Retrieved from www.training.cochrane.org/handbook.

26. Hedges, L. V., \& Olkin, I. (1985). Statistical Methods for MetaAnalysis (p. 369). Academic Press.

27. Brown, D. W., et al. (2004). Associations between physical activity dose and health-related quality of life. Medicine \& Science in Sports \& Exercise, 36(5), 890-896. https://doi.org/10.1249/01. MSS.0000126778.77049.76

28. Gu, X., Chen, Y., \& Collins, J. (2013). Perceived barriers mediate students' physical activity and quality of life. Research Program Schedule, Research Quarterly for Exercise and Sport, 85(1), 66-66.

29. Noce, F., et al. (2016). A 6-month comparison of quality of life and mood states between physically active and sedentary college students. Medicina, 49(1), 9-16.

30. Zahran, H. S., et al. (2007). Health-related quality of life and behaviors risky to health among adults aged 18-24 years in secondary or higher education-United States, 2003-2005. Journal of Adolescent Health, 41(4), 389-397. https://doi.org/10.1016/j. jadohealth.2007.05.011

31. Cadarso Suárez, A., et al. (2017). Calidad de vida relacionada con la salud y su relación con la adherencia a la dieta mediterránea y la actividad física en universitarios de Galicia. Nutrición Clínica y Dietética Hospitalaria, 37(2), 42-49. https://doi.org/ 10.12873/372cadarso

32. Carothers, C. de S.L. (2008). Minimum levels of physical activity and perceived quality of life [Internet]. ProQuest Dissertations and Theses. Ann Arbor: University of North Texas. Retrieved from https://search.proquest.com/docview/304538057?accou ntid=26646.

33. Corrigan, V. K., Pierce, B. J., Hosig, K. (2018). Dog ownership, physical activity, and health-related quality of life in veterinary students: A cross-sectional study. Journal of Veterinary Medical Education, 45(1), 51-63. Retrieved from http://www.embase. $\mathrm{com} / \mathrm{search} /$ results? subaction=viewrecord $\&$ from $=$ export\&id $=$ L621218378.

34. Dubois, E. J. (2006). Assessment Of Health-Promoting Factors In College Students Lifestyles Submitted to the Graduate Faculty of Auburn University in Partial Fulfillment of the Requirements for the Degree of Doctor of Education Auburn. Alabama: Auburn University.

35. Faílde Garrido, J. M., et al. (2019). Evolution of quality of life and health-related behaviors among Spanish university students. The International Journal of Health Planning and Management, 34(3), 259-268. https://doi.org/10.1002/hpm.2692

36. Fallahzadeh, H. (2012). HealthRelated Quality of Life and Associated Factors Among Iranian University Students [Internet]. $J C H R, 1(2), 122-130$. Retrieved from http://jhr.ssu.ac.ir/artic le-1-49-en.html

37. Grant, N., Wardle, J., \& Steptoe, A. (2009). The relationship between life satisfaction and health behavior: A cross-cultural analysis of young adults. International Journal of Behavioral Medicine, 16(3), 259-268. https://doi.org/10.1007/ s12529-009-9032-x

38. Herbert, C., et al. (2020). Regular physical activity, short-term exercise, mental health, and well-being among university students: The results of an online and a laboratory study. Frontiers in Psychology, 11, 509. https://doi.org/10.3389/fpsyg.2020. 00509

39. Hidalgo-Rasmussen, C. A., Ramírez-López, G., HidalgoSanMartín, A. (2013). Atividade física, comportamento sedentário e qualidade de vida em adolescentes universitários de Ciudad Guzmán, Jalisco, México. Ciência saúde coletiva] 18(7), 1943-1952. doi:https://doi.org/10.1590/S1413-8123201300 0700009 .
40. Hossein, S. D., et al. (2010). Determinants of health -promoting lifestyle among university of medical science students, Yazd, Iran. European Journal of Medical Research, 15(1), 200-201.

41. Jamali, A., et al. (2013). Medical, students' health-related quality of life: Roles of social and behavioural factors. Medical Education, 47(10), 1001-1012. https://doi.org/10.1111/medu.12247

42. Khazaal, Y., et al. (2016). OR-52 internet gambling behaviors: A latent class analysis OR-53 Evaluation of the nine Internet Gaming Disorder criteria proposed in the DSM-5 OR-54 understanding the problematic practice of physical exercise: Associations with quality of life. Impuls, 5, 23-24.

43. Kotbagi, G., et al. (2014). Pratique problématique d'exercice physique: Un cas clinique. Annales Médico-psychologiques, revue psychiatrique, 172(10), 883-887.

44. Kupcewicz, E., et al. (2020). Analysis of the relationship between stress intensity and coping strategy and the quality of life of nursing students in Poland, Spain and Slovakia. International Journal of Environmental Research and Public Health, 17(12), 1-16. https://doi.org/10.3390/ijerph17124536

45. Kvintova, J., Kudlacek, M., \& Sigmundova, D. (2016). Active lifestyle as a determinant of life satisfaction among university students. Anthropologist, 24(1), 179-185. https://doi.org/10. 1080/09720073.2016.11892004

46. Lins, L., et al. (2015). Health-related quality of life of students from a private medical school in Brazil. International Journal of Medical Education, 6, 149-4154. https://doi.org/10.5116/ijme. 563a.5dec

47. Mašina, T., et al. (2017). Differences in health-promoting lifestyle profile among croatian medical students according to gender and year of study. Acta Clinica Croatica, 56(1), 84-91. https:// doi.org/10.20471/acc.2017.56.01.13

48. Nacar, M., et al. (2014). Health promoting lifestyle behaviour in medical students: A multicentre study from Turkey. Asian Pacific Journal of Cancer Prevention, 15(20), 8696-8974. https://doi. org/10.7314/apjcp.2014.15.20.8969

49. Obrecht, A., et al. (2015). Análise da qualidade do sono em estudantes de graduação de diferentes turnos. Revista Neurociências, 23(2), 205-210. https://doi.org/10.4181/RNC.2015.23.02. 998.6p.]

50. Odom, S. K. (2001). Assessment of health-promoting lifestyle in male and female college students. Medical Journal. https://doi. org/10.4103/mjdrdypu.mjdrdypu_93_21

51. Partonen, T., et al. (1988). Randomized trial of physical exercise alone or combined with bright light on mood and health-related quality of life. Psychological Medicine, 28(6), 1359-1364. https://doi.org/10.1017/s0033291798007491

52. Pengpid, S., \& Peltzer, K. (2013). Physical inactivity and associated factors among university students in South Africa. African Journal for Physical, Health Education, Recreation and Dance, 19, 143-153. https://doi.org/10.1007/s00038-015-0680-0

53. Pedišić, Ž, et al. (2015). Are total, intensity- and domain-specific physical activity levels associated with life satisfaction among university students? PLoS ONE, 10, 2. https://doi.org/10.1371/ journal.pone. 0118137

54. Rachmawati, M. R., Sidarta, N., \& Mediana, D. (2019). Differences in physical activity, lactic acid concentration, and quality of life between gender among first year medical students. Maj Kedokt Bandung, 51(4), 194-200. https://doi.org/10.15395/mkb. v51n4.1636

55. Ramsay, J. E., et al. (2015). Divergent pathways to influence: Cognition and behavior differentially mediate the effects of optimism on physical and mental quality of life in Chinese university students. Journal of Health Psychology, 20(7), 963-973. https:// doi.org/10.1177/1359105313504441

56. Sabbah, I., et al. (2013). Health related quality of life of university students in Lebanon: Lifestyles behaviors and 
socio-demographic predictors. Health, 5(7), 1-12. https://doi. org/10.4236/health.2013.57A4001

57. Salari, S., et al. (2017). Examining the health-promoting lifestyle and its related factors among the nursing students of Jiroft university of medical sciences. Indian Journal of Public Health Research \& Development, 8(1), 342-346. https://doi.org/10. 5958/0976-5506.2017.00068.7

58. Saldiran, T. Ç., Tanriverdi, M., \& Çakar, E. (2019). Relationship between physical activity and healthy lifestyle behaviors in college students. Journal of Basic and Clinical Health Sciences, 3, 58-62. https://doi.org/10.30621/jbachs.2019.567

59. Salgado Espinosa, M. L., \& Álvarez Bermúdez, J. (2020). Autoeficacia: Relación con los hábitos de salud y la calidad de vida en universitarios del noreste de México. Revista Española de Comunicación en Salud. https://doi.org/10.20318/recs.2020. 5166

60. Serinolli, M. I., \& El-Mafarjeh, E. (2015). Impacto da prática de atividade física na qualidade de vida dos acadêmicos de Medicina da Universidade Nove de Julho (Uninove). ConScientiae Saúde, 14(4), 627-633. https://doi.org/10.5585/ConsS aude.v14n4.5958

61. Tassini, C. C., et al. (2017). Avaliação Do Estilo De Vida Em Docentes Da Área Da Saúde. Revista da Sociedade de Cardiologia do Estado de São Paulo, 27(3), 118-123. https://doi.org/ 10.5935/2359-4802.20170024

62. Tol, A., et al. (2013). Health-promoting lifestyle and quality of life among undergraduate students at school of health, Isfahan university of medical sciences. Journal of Education Health Promotion, 2(11), 29-32. https://doi.org/10.4103/2277-9531. 108006

63. Vaez, M., \& Laflamme, L. (2003). Health behaviors, self-rated health, and quality of life: A study among first-year Swedish University Students. Journal of American College Health, 51(4), 156-162. https://doi.org/10.1080/07448480309596344

64. Wald, A., et al. (2014). Associations between healthy lifestyle behaviors and academic performance in U.S. undergraduates: a secondary analysis of the American College Health Association's National College Health Assessment II. American Journal of Health Promotion, 28(5), 298-305. https://doi.org/10.4278/ajhp. 120518-QUAN-265

65. Wei, C. N., et al. (2012). Assessment of health-promoting lifestyle profile in Japanese university students. Environmental Health and Preventive Medicine, 17(3), 222-227. https://doi. org/10.1007/s12199-011-0244-8

66. Werch, C. E. C., Moore, M. J., \& Ames, S. C. (2011). Are effects from a brief multiple behavior intervention for college. Preventive Medicine, 50(1-2), 1-13. https://doi.org/10.1016/j.ypmed. 2009.12.010

67. Kizilci, M. H., et al. (2015). Investigation of physical activity levels of undergraduate students. Fizyoterapi Rehabilitasyon, 26(2), 66

68. Kolokoltsev, M. M., et al. (2020). Physical activity as a factor to improve the quality of student life. Obraz i Nauk, 22(5), 150-168.

69. Maciel, E. S., et al. (2013). The relationship between physical aspects of quality of life and extreme levels of regular physical activity in adults. Cadernos de Saúde Pública, 29(11), 22512260. https://doi.org/10.1590/0102-311x00178512

70. Peleias, M., et al. (2017). Leisure time physical activity and quality of life in medical students: results from a multicenter study. BMJ Open Sport \& Exercise Medicine. https://doi.org/10.1136/ bmjsem-2016-000213

71. Dunn, J. (2011). Ecological Analysis of Physical Activity and Health-related Quality of Life in Female College Students., thesis; Denton, Texas, University of North Texas Libraries, UNT Digital Library, https://digital.library.unt.edu.
72. Goldsby, E. (2018). The Relationship Between Health-Related Quality Of Life, Physical Activity and Sleep on BMI And Life Satisfaction. Thesis. School of Public Health, Indiana University.

73. Joseph, R. P., et al. (2014). Physical activity and quality of life among university students: Exploring self-efficacy, self-esteem, and affect as potential mediators. Quality of Life Research, 23(2), 659-667. https://doi.org/10.1007/s11136-013-0492-8

74. Neves, C. (2017). The Effect of Physical Activity on The HealthRelated Quality of Life of College Students. Dissertation. Hofstra University Hempstead, New York.

75. Zhang, T., et al. (2016). College students' physical activity and health-related quality of life: An achievement goal perspective. Research Quarterly for Exercise and Sport, 87(2), 182-190. https://doi.org/10.1080/02701367.2016.1159279

76. Zhang, T., et al. (2018). Ecological analysis of college women's physical activity and health-related quality of life. Women and Health, 58(3), 260-277. https://doi.org/10.1080/03630242.2017. 1296057

77. Çiçek, G. (2018). Quality of life and physical activity among university students. Universal Journal of Educational Research, 6(6), 1141-1148. https://doi.org/10.13189/ujer.2018.060602

78. Kilinç, H., et al. (2016). Physical activity level and quality of life of university students. Journal of Human Sciences, 13(3), 3794-3806. http://orcid.org/0000-0002-6499-0555.

79. Kocaaga, E., et al. (2018). Relationship between physical activity, functional capacity, quality of life and sleep quality in healthy subjects. Fizyoterapi Rehabilitasyon, 29, 1.

80. Yildirim, M., \& Bayrak, C. (2019). The participation of university students in physical activities based on sport and the effect of the students'quality of life on academic achievement and socialisation (sample of Eskisehir Osmangazi University). HU Journal of Education, 34(1), 123-144. https://doi.org/10.16986/HUJE. 2017032928

81. Park, J. Y., \& Kim, N. (2013). Relationships between physical activity, health status and quality of life of university students. Journal of Korean Public Health Nursing., 27(1), 153-165. https://doi.org/10.5932/JKPHN.2013.27.1.153

82. Joo, M. H. (2018). Associations between physical activity, stress, interpersonal relationship and quality of life in university students. Indian Journal of Public Health Research and Development, 9(9), 480. https://doi.org/10.5958/0976-5506.2018.01045.8

83. Mak, Y. W., et al. (2018). Health promoting lifestyle and quality of life among Chinese nursing students. Primary Health Care. Research \& Development, 19, 629-636. https://doi.org/10.1017/ S1463423618000208

84. Kokic, I. S., Znika, M., \& Brumnic, V. (2019). Physical activity, health-related quality of life and musculoskeletal pain among students of physiotherapy and social sciences in Eastern Croatia-cross-sectional survey. Annals of Agricultural and Environmental Medicine, 26(1), 182-190. https://doi.org/10.26444/ aaem $/ 102723$

85. Pedišić, Ž, et al. (2014). Domain-specific physical activity and health-related quality of life in university students. European Journal of Sport Science, 14(5), 492-499. https://doi.org/10. 1080/17461391.2013.844861

86. Khan, B. A., \& Hassandra, M. (2016). Interaction of physical activity, mental health and quality of life: A study on university students in Pakistan. Journal of Physical Education Research, 3(2), 01-10.

87. Kruger, S., \& Sonono, E. (2016). Physical activity and psychosomatic related health problems as correlates of quality of life among university students. Journal of Psychology in Africa, 26(4), 357-362. https://doi.org/10.1080/14330237.2016.11859 07

88. Lemos, D. M. C., Orozco-Vargas, L. C., \& Cruz, G. I. N. (2014). Calidad De Vida En Estudiantes Universitarios Evaluación De 
Factores Asociados/Quality of life In college students evaluation of associated factors. Revista Costarricense de Salud Pública, 23(2), 117-123.

89. Massidda, M., Cugusi, L., \& Mathieu, A. (2014). Physical activity levels and health-related quality of life in young Italian population. Journal of Sports Medicine and Physical Fitness, 55(5), 506-512.

90. Mendoza, F. J., Parra, G., \& Bastardo, Y. M. (2013). Preliminary results quality of life, physical activity, and sedentary behavior in college students. Value In Health, 16, 665-728.

91. Nowak, O. F., Bożek, A., \& Blukacz, M. (2019). Physical activity, sedentary behavior, and quality of life among university students. BioMed Research International. https://doi.org/10.1155/ 2019/9791281

92. Pekmezovic, T., et al. (2011). Factors associated with healthrelated quality of life among Belgrade University students. Quality of Life Research, 20(3), 391-397. https://doi.org/10.1007/ s11136-010-9754-x

93. Pourranjbar, M., \& Zeytoonli, A. H. (2019). Lifestyle, quality of life and physical activity barriers among female students of Kerman University of Medical Sciences. Iran. Journal of Kerman University of Medical Sciences, 26(3), 214-225. https://doi.org/ 10.22062/JKMU.2019.89502

94. Vo, T. Q., Nguyen, H. T. T., \& Ta, A. P. N. (2020). Effect of sociodemographic factors on quality of life of medical students in southern Vietnam: A survey using the WHOQOL-BREF assessment. Journal of Pharmacy \& Pharmacognosy Research, 8(3), 211-224.

95. Souza, I., et al. (2015). Níveis de atividade física e estágios de mudança de comportamento de universitários da área de saúde. Revista Brasileira de Atividade Física \& Saúde, 20(6), 608-608. https://doi.org/10.12820/rbafs.v.20n6p608

96. Mello, A. L. S. F., Moyses, S. T., \& Moyses, S. J. (2010). A universidade promotora de saúde e as mudanças na formação profissional. Interface (Botucatu), 14(34), 683-692. https://doi. org/10.1590/S1414-32832010005000017

97. Plotnikoff, R. C., et al. (2015). Effectiveness of interventions targeting physical activity, nutrition and healthy weight for university and college students: A systematic review and meta-analysis. International Journal of Behavioral Nutrition and Physical Activity, 1, 12-45. https://doi.org/10.1186/s12966-015-0203-7

98. SanRomán-Mata, S., Puertas-Molero, P., Ubago-Jiménez, J., \& González-Valero, G. (2020). Benefits of physical activity and its associations with resilience, emotional intelligence, and psychological distress in University Students from Southern Spain. International Journal of Environmental Research and Public Health, 17(12), 44-74. https://doi.org/10.3390/ijerph17124474

99. Bize, R., Johnson, J. A., \& Plotnikoff, R. C. (2007). Physical activity level and health-related quality of life in the general adult population: a systematic review. Preventive Medicine, 45(6), 401-415.

100. Pucci, G. C., Rech, C. R., Fermino, R. C., \& Reis, R. S. (2012). (2012) Association between physical activity and quality of life in adults. Revista de Saude Publica, 46(1), 166-179. https://doi. org/10.1590/s0034-89102012000100021

101. Wu, X. Y., Han, L. H., Zhang, J. H., Luo, S., Hu, J. W., \& Sun, K. (2017). The influence of physical activity, sedentary behavior on health-related quality of life among the general population of children and adolescents: A systematic review. PLOS ONE., 12(11), 10187668. https://doi.org/10.1371/journal.pone.0187668
102. Vagetti, G. C., Barbosa Filho, V. C., Moreira, N. B., Oliveira, V. D., Mazzardo, O., \& Campos, W. D. (2014). Association between physical activity and quality of life in the elderly: A systematic review, 2000-2012. Brazilian Journal of Psychiatry, 36(1), 76-88. https://doi.org/10.1590/1516-4446-2012-0895

103. Berwanger, O., Suzumura, E. A., Buehler, A. M., \& Oliveira, J. B. (2007). Como avaliar criticamente revisões sistemáticas e metanálises? Revista Brasileira de Terapia Intensiva, 19(4), $475-480$.

104. Legramanti Rodrigues, C., Klarmann Ziegelmann, P. (2011). Metanálise: Um Guia Prático. Clinical \& Biomedical Research, 30(4).

105. Chow, S. K. Y., \& Choi, E. K. Y. (2019). Assessing the mental health, physical activity levels, and resilience of today's junior college students in self-financing institutions. International Journal of Environmental Research and Public Health, 16, 17. https:// doi.org/10.3390/ijerph16173210

106. Siegmann, P., et al. (2018). Resilience to suicide ideation: A cross-cultural test of the buffering hipótese. Clinical Psychology \& Psychotherapy, 25(1), 1-9. https://doi.org/10.1002/cpp.2118

107. Fedewa, A. L., \& Ahn, S. (2011). Os efeitos da atividade física e aptidão física no desempenho das crianças e resultados cognitivos: Uma meta-análise. Research Quarterly for Exercise and Sport, 82, 521-535.

108. Wu, X. (2015). Low physical activity and high screen time can increase the risks of mental health problems and poor sleep quality among Chinese college students. PLOS ONE, 10(3), e0119607. https://doi.org/10.1371/journal.pone.0119607

109. Ghrouz, A. K., Noohu, M. M., Dilshad Manzar, M., Warren Spence, D., BaHammam, A. S., \& Pandi-Perumal, S. R. (2019). Physical activity and sleep quality in relation to mental health among college students. Sleep Breath, 23(2), 627-634. https:// doi.org/10.1007/s11325-019-01780-z

110. Sloan, R. A., et al. (2009). Associações entre Aptidão Cardiorrespiratória e Qualidade de Vida Relacionada à Saúde. Health and Quality of Life Outcomes, 7, 47. https://doi.org/10.1186/ 1477-7525-7-47

111. Puetz, T. W. (2006). Physical activity and feelings of energy and fatigue: Epidemiological evidence. Sports Medicine (Auckland, N. Z.), 36(9), 767-780. https://doi.org/10.2165/00007256-20063 6090-00004

112. Ozdemir,F, et al. (2020). The role of physical activity on mental health and quality of life during COVID-19 outbreak: A crosssectional study. European Journal of Integrative Medicine, 40, 101248. https://doi.org/10.1016/j.eujim.2020.101248

113. Qi, M. (2020). Physical activity, health-related quality of life, and stress among the chinese adult population during the COVID-19 pandemic. International Journal of Environmental Research and Public Health, 17(18), 64-94. https://doi.org/10.3390/ijerph1718 6494.PMID:32906604;PMCID:PMC7558071

114. Gallo, L. A. (2020). The impact of isolation measures due to COVID-19 on energy intake and physical activity levels in Australian University Students. Nutrients, 12(6), 1865. https://doi. org/10.3390/nu12061865

Publisher's Note Springer Nature remains neutral with regard to jurisdictional claims in published maps and institutional affiliations. 


\section{Authors and Affiliations}

Lívia Carvalho Sette Abrantes ${ }^{1,2}$ (D) Núbia de Souza de Morais ${ }^{2}$. Vivian Siqueira Santos Gonçalves ${ }^{3}$ (D) Sarah Aparecida Vieira Ribeiro ${ }^{2} \mathbb{D}$. Catarina Maria Nogueira de Oliveira Sediyama ${ }^{4}$.

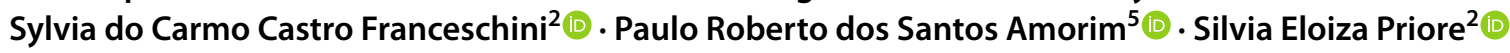

Núbia de Souza de Morais nubia.s.morais25@gmail.com

Vivian Siqueira Santos Gonçalves vivian.goncalves@unb.br

Sarah Aparecida Vieira Ribeiro sarah.vieira@ufv.br

Catarina Maria Nogueira de Oliveira Sediyama catarina.sediyama@ufv.br

Sylvia do Carmo Castro Franceschini sylvia@ufv.br

Paulo Roberto dos Santos Amorim pramorim@ufv.br

Silvia Eloiza Priore sepriore@ufv.br
1 Federal University of Viçosa (UFV), Viçosa, Brazil

2 Department of Nutrition and Health, Ed. Biological Sciences Center II, Universidade Federal de Viçosa (UFV), Avenida Peter Henry Rolfs, S/no., University Campus, Viçosa, MG CEP: 36570-900, Brazil

3 Graduate Program in Public Health, University of Brasilia (UnB), Brasilia, Brazil

4 Department of Medicine and Nursing, Federal University of Viçosa (UFV), Viçosa, Brazil

5 Department of Physical Education, The Federal University of Viçosa (UFV), Viçosa, Brazil 